\title{
Effect of Initiation Location within Blasthole on Blast Vibration Field and Its Mechanism
}

\author{
Qidong Gao, ${ }^{1}$ Wenbo Lu $\mathbb{D}^{2}{ }^{2}$ Zhendong Leng $\mathbb{D}^{3,4}{ }^{3,}$ Zhaowei Yang, ${ }^{3}$ Yuzhu Zhang, \\ and Haoran $\mathrm{Hu} \mathbb{( i D}^{5}$ \\ ${ }^{1}$ School of Highway, Chang'an University, Xi'an 710064, China \\ ${ }^{2}$ State Key Laboratory of Water Resources and Hydropower Engineering Science, Wuhan University, Wuhan 430072, China \\ ${ }^{3}$ Changjiang River Scientific Research Institute, Wuhan 430010, China \\ ${ }^{4}$ Gezhouba Group Explosive Co., Ltd, Chongqing 401121, China \\ ${ }^{5}$ Changjiang Institute of Survey, Planning, Design and Research, Wuhan 430010, China
}

Correspondence should be addressed to Wenbo Lu; wblu@whu.edu.cn and Zhendong Leng; zdleng@whu.edu.cn

Received 16 September 2019; Accepted 15 November 2019; Published 6 December 2019

Academic Editor: Francesco Pellicano

Copyright ( 2019 Qidong Gao et al. This is an open access article distributed under the Creative Commons Attribution License, which permits unrestricted use, distribution, and reproduction in any medium, provided the original work is properly cited.

\begin{abstract}
In drill and blast, the explosive filled in each blasthole is cylindrically shaped and generally initiated by the detonator. Thus, the effect of the initiation location must be addressed, as it determines the detonation direction along the entire column explosive. In this paper, the effect of the initiation location on blast vibration field and its acting mechanism were comprehensively investigated through the theoretical, computational, and experimental approaches. The results indicate that the initiation location plays an important role in the blast vibration filed of the cylindrical charge. The underlying effect of the initiation location can be regarded as the combined results of the energy distribution and phase delay effects of the column explosive source. The behavior of the rock mass in the single-hole blasting experiment demonstrates that the explosion energy is preferentially transmitted to the forward direction of the detonation wave. The seed wave-based computation model verifies that owing to the phase delay effect, the blast vibration field of the cylindrical charge is not uniformly distributed and is strengthened at the forward direction of the detonation wave. The production blasting experiment indicates that the ground PPV under bottom initiation is 61.3\% 211.7\% larger than that under top initiation. In addition, the effect of the initiation location is sensitive to the charge length $L$ and the denotation velocity $D$. Meanwhile, the effect of the initiation location vanishes with distance. The present study provides valuable reference for understanding the effect of the initiation location on blast vibration in drill and blast.
\end{abstract}

\section{Introduction}

Drill and blast, as an economical, efficient, and adaptable method, is still widely used in mining, hydropower, traffic, and civil engineering fields [1-5]. In practice, the blastholes are charged either by the finished explosive charge (Figure 1(a)) or by the semifinished charging vehicle (Figure 1(b)). Anyway, the explosives filled in the blastholes are all cylindrical charges with large length-to-diameter ratio. The cylindrical charge within each blasthole is usually initiated by the detonator. Due to the geometrical and finite velocity of detonation $(\mathrm{VoD})$ characteristics, the detonation reaction has time and directional effects along the entire length of the column explosive [6]. The initiation location actually determines the propagation direction of the detonation wave. Therefore, the effect of the initiation location must be addressed in drill and blast.

Many investigations on the effect of the initiation location were conducted by various researchers. Fry et al. and Sichel investigated the effect of the detonation direction on the dynamic behavior of the surrounding medium $[7,8]$. Zhang outlined the relationship of the ore extraction with the detonator location and conducted many field experiments in LKAB Malmberget mine in Sweden [9]. Long ascertained the effect of the initiation location on rock fragmentation through many field experiments and 


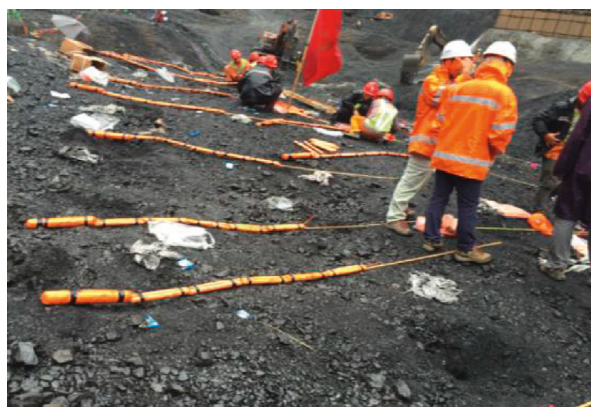

(a)

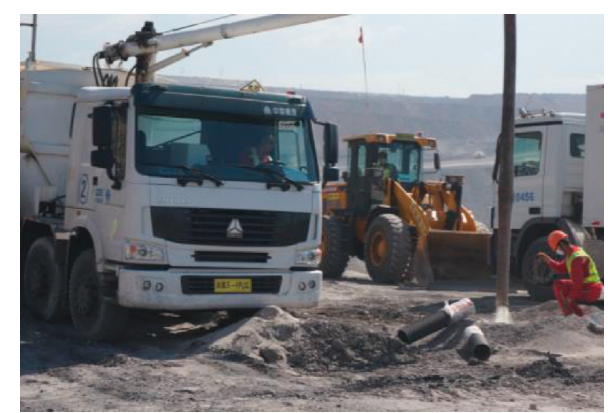

(b)

FIGURE 1: Scene of the charging process in drill and blast: (a) finished explosive charge; (b) semifinished charging vehicle.

provided a convincing explanation from the point of the usage ratio of explosive energy [10]. Onederra et al. found that the rock damage degree at the top section is larger than that at the blasthole bottom if the explosive charge is bottom initiated, when simulating the blasting process by the HSBM (hybrid stress blasting model) method [11]. Liu et al. demonstrated that the formation of rock toes at the blasthole bottom or rock boulders at the top section are both closely associated with the initiation location during the bench blasting, through the numerical and experimental investigation [12]. Leng et al. compared the transmission mechanisms of the explosion energy between side-initiation and end-initiation modes and revealed the partition of the shock wave and the gas energy [13]. Gao et al. discussed the effect of the initiation location on the distribution and utilization of the explosion energy in rock blasting and gave some suggestions on the choice of the initiation location in practice [14]. The above studies mainly focused on the behavior of the blasting medium under differing initiation locations, such as the rock fragmentation. Unlike a spherical charge where the source radiation is the same in all directions [15], the source radiation pattern of the cylindrical charge has its unique characteristic [16-19]. Thus, a number of researchers also put emphasis on the cylindrical charge itself. Heelan first discovered that the $\mathrm{P}$ and $\mathrm{S}$ waves are simultaneously beamed out from a short column explosive, and they are both channeled in certain directions and travel at different speeds [16]. Blair derived the source radiation from an extended cylindrical charge, assuming the seed wave of Heelan radiation [20]. Liu et al. calculated the strain waves generated by a cylindrical charge and found that the strain amplitude varies with the gauge orientation relative to the initiation point [21]. Triviño et al. discovered that the amplitude and frequency spectrum of the blast vibration induced by a cylindrical charge is significantly affected by the detonation direction, after analyzing much collected data from the underground mining [22].

As was stated above, the effect of the initiation location usually embodies as the behavior of the blasting medium (such as the rock fragmentation) and the source radiation of the explosive charge itself. However, the previous studies mostly emphasized on the rock fragmentation, but the effect of the initiation location on blast vibration field as well as its acting mechanism is still not well studied. As a result, the bottom initiation was recommended by most previous researchers, as it benefits for the rock fragmentation $[9,10]$. The effect of the initiation location on blast vibration field is not properly considered, whereas the blast vibration is always termed as the most important adverse effect in blasting [23-26] because it greatly influences the rock behaviors [27-29], the stability of structures, and the safety of surrounding facilities, etc. In this paper, the acting mechanism of the initiation location was analyzed from the view of the energy distribution and phase delay effects of the column explosive source. Then the blast vibration fields of the cylindrical charge under differing initiation locations were compared via the seed wave-based computation model. At last, two field experiments, including a single-hole blasting experiment and a production blasting experiment, were implemented to validate the effect of the initiation location on blast vibration. The present study is of interest to the widely used drill and blast due to the potential of better control of the blast vibration.

\section{Acting Mechanism of the Initiation Location}

2.1. Energy Distribution Effect along the Detonation Direction. The detonation of explosive is a complex chemical reaction process, with the chemical energy transforming to the internal and kinetic energy of gaseous products. According to the Chapman-Jouguet theory, the detonation reaction comes to a steady and balanced state when the propagation speed of the detonation wave tends to be a constant. Figure 2 illustrates the detonation of explosive and the propagation of the detonation wave, where $D$ denotes the steady $\mathrm{VoD}$. The detonation wave is actually a kind of shock wave propagating in the explosive. Apparently, the detonation reaction has time and directional effects along the entire length of the column explosive. Thus, the initiation location will inevitably affect the distribution of the detonation products and explosion energy.

As shown in Figure 3, Zhang et al. [30] used a onedimensional flow model to analyze the energy distribution assuming that the explosive is placed in a vacuum rigid pipe. The total length of the charge is defined as $l$, with length $b$ and $a$, respectively, located at the left and right sides $(l=b+a, b \leq a)$. The initial density and velocity 


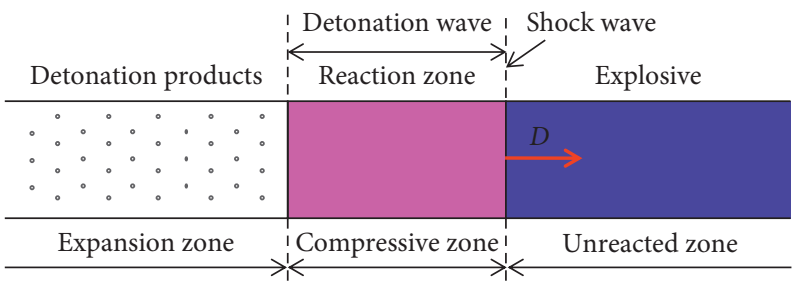

Figure 2: Illustration of the detonation of explosive and the propagation of the detonation wave.

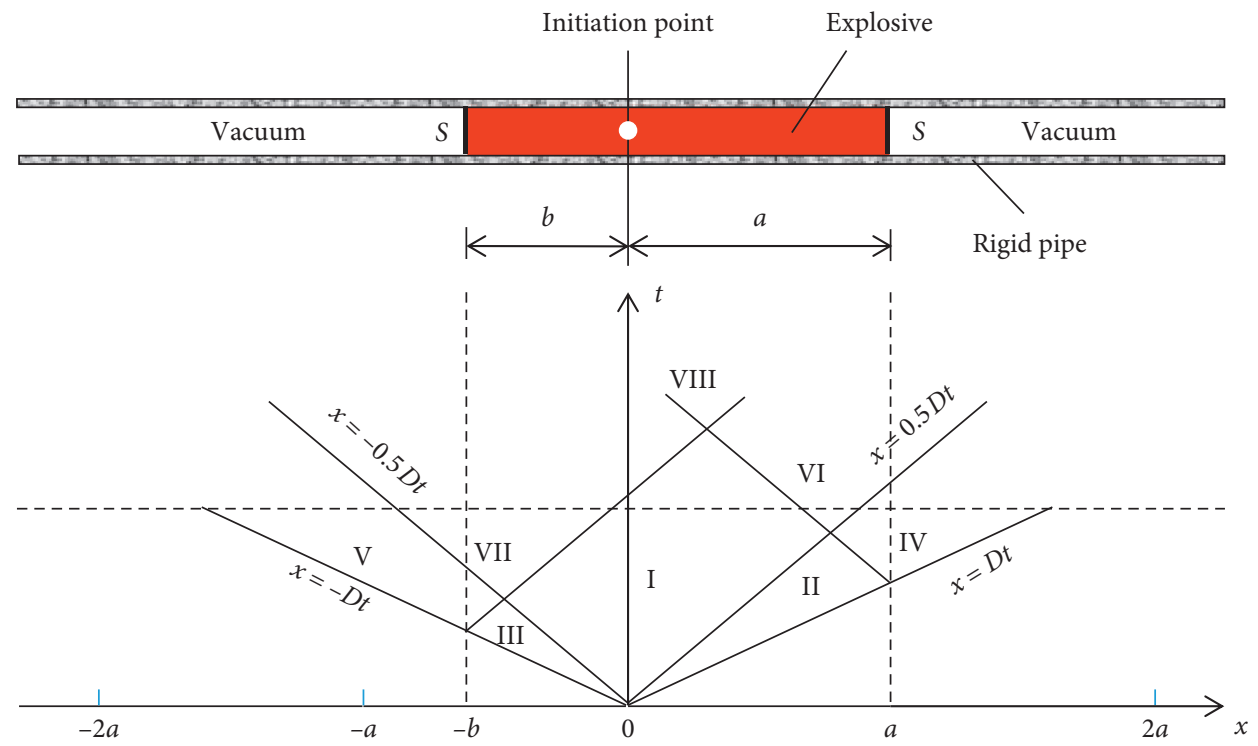

FIgURE 3: One-dimensional flow model of the cylindrical charge and the partition of flow fields.

of the explosive are $\rho_{0}$ and $D_{0}$, and the section area of the charge is $S$. Eight different kinds of flow fields will be formed in the pipe after a certain time. According to the partition of flow fields (Figure 3), the mass and energy distribution can be computed by equations (1) and (2), respectively:

$$
\begin{aligned}
& \left\{\begin{array}{l}
M_{b}=\frac{1}{9} \rho_{0} S(4 a+5 b), \\
M_{a}=\frac{1}{9} \rho_{0} S(5 a+4 b),
\end{array}\right. \\
& \left\{\begin{array}{l}
E_{b}=\frac{1}{27} \rho_{0} S D^{2}\left(\frac{11}{16} a+b\right), \\
E_{a}=\frac{1}{27} \rho_{0} S D^{2}\left(a+\frac{11}{16} b\right),
\end{array}\right.
\end{aligned}
$$

where $M_{b}$ and $M_{a}$ are, respectively, the mass of detonation products that are distributed to the left and right sides and $E_{b}$ and $E_{a}$ are, respectively, the explosion energy distributed to the left and right sides. If the charge is initiated at the left end $(b=0, a=l)$, equations (1) and (2) can be simplified as equations (3) and (4), respectively:

$$
\left\{\begin{array}{l}
M_{b}=\frac{4}{9} \rho_{0} S l \\
M_{a}=\frac{5}{9} \rho_{0} S l
\end{array}\right.
$$

$$
\left\{\begin{array}{l}
E_{b}=\frac{11}{27} \frac{l}{16} \rho_{0} S D^{2}, \\
E_{a}=\frac{16}{27} \frac{l}{16} \rho_{0} S D^{2} .
\end{array}\right.
$$

Equations (1) and (2) show that the mass and energy distribution is closely associated with the length parameters $a$ and $b$. It is not hard to draw from equations (3) and (4) that the detonation products and the explosion energy are preferentially distributed to the forward direction of the detonation wave. If the charge is initiated at the left end, the mass of detonation products and the explosion energy distributed to the right side are, respectively, 1.25 and 1.45 times of that distributed to the left side.

2.2. Phase Delay Effect of the Charge Elements. As shown in Figure 4(a), the blast stress field generated by a cylindrical 


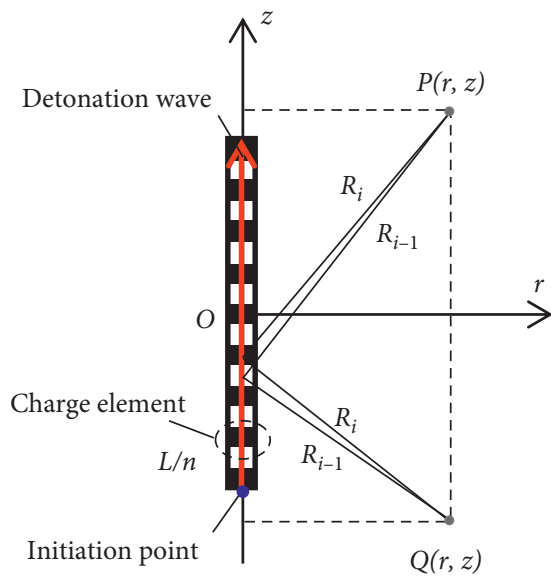

(a)

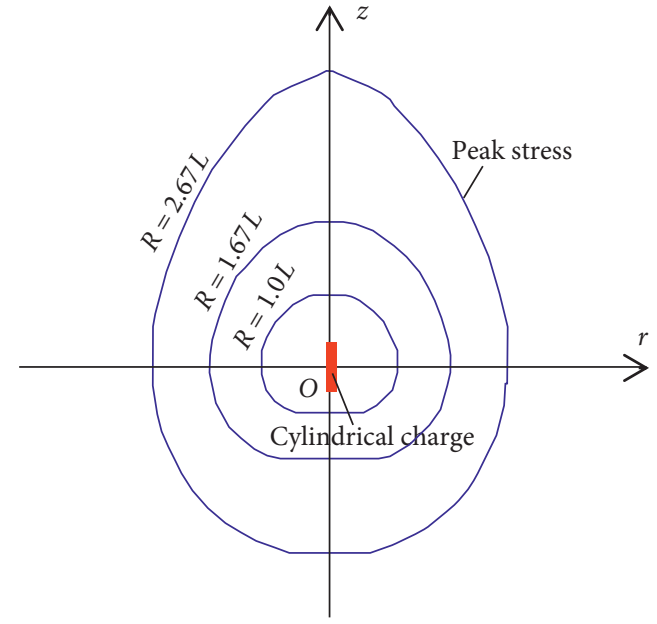

(b)

FIGURE 4: Illustration of the phase delay effect of the charge elements. (a) Computation model of the blast stress field of cylindrical charge. (b) Normalized peak stress at the same distance from the charge center $O$, and the peak stress is represented by the normalized distance from $O$ in the polar coordinate system.

charge is usually approximated by summing the contributions of the short charge elements along the entire length $[20,31]$. The total length is $L$, and it is divided into $n$ elements. The source function of each charge element can be described by the following equation:

$$
f(R, t)= \begin{cases}A R^{-\alpha} g(t-\tau), & t \geq \tau, \\ 0, & t<\tau,\end{cases}
$$

where $A R^{-\alpha}$ is the amplitude of the stress wave at distance $R$ and shows an attention of $R^{-\alpha}, g(t)$ describes the wave shape of the charge element, and $\tau$ is the travel time of the stress wave from each charge element to the observation point.

As the explosive velocity of detonation ( $\mathrm{VoD}$ ) is not infinitely high but embodies as the same level of the sonic velocity of rock mass, the phase delay effect must be considered in the superposition. The stress wave emitted by element $(i-1)$ is $L / n D$ earlier than that emitted by element $i$. Take the bottom initiation as an example, if the observation point $P$ is located at the top side, the stress amplitude induced by element $i$ is larger than that induced by element $(i-1)$ because the subsequent element $i$ is relatively closer to the observation point. As a result, the stress superposition of the subsequent charge elements for the point $P$ is gradually strengthened. On the contrary, the contributions from the subsequent charge elements for the point $Q$ located at the bottom side become weaker and weaker. Figure 4(b) illustrates the contour lines of the normalized peak stress. It indicates that the blast stress field of the cylindrical charge is not uniformly distributed. If the cylindrical charge is bottom initiated, the blast stress at the top side is larger than that at the bottom side. Actually, the blast stress field is strengthened at the forward direction of the detonation wave. This phenomenon is also called the end effect of the cylindrical charge.

As stated in Figure 4, the acting mechanism of the initiation location can be interpreted as the following two points: (1) The energy distribution of the cylindrical charge is closely associated with the initiation location, as it determines the detonation direction as well as the flow fields of detonation products. (2) The blast stress field of a cylindrical charge is not uniformly distributed but has the end effect that is caused by the phase delay effect. The underlying mechanism lies in the geometrical characteristic (large length-to-diameter ratio) and finite $\mathrm{VoD}$ of the explosive charge.

\section{Comparative Study of the Blast Vibration Field under Differing Initiation Locations}

3.1. Seed Wave-Based Computation Model. As illustrated in Figure 5, Heelan made a vital contribution to the source radiation pattern of a short column source, and he discovered that both $\mathrm{P}$ and $\mathrm{S}$ waves simultaneously radiated from a finite length of explosive [16]. Besides, the P and S waves are channeled in certain directions and travel at different speeds. The following equations give the Heelan radiation of a short explosive column:

$$
\begin{aligned}
& {\left[\begin{array}{c}
u_{\mathrm{P}} \\
w_{\mathrm{P}}
\end{array}\right]=\left[\frac{F_{1}(\varphi)}{R} \frac{\mathrm{d}}{\mathrm{d} t}\left\{p\left(t-\frac{R}{C_{\mathrm{P}}}\right)\right\}\right]\left[\begin{array}{c}
\sin \varphi \\
-\cos \varphi
\end{array}\right],} \\
& {\left[\begin{array}{l}
u_{\mathrm{S}} \\
w_{\mathrm{S}}
\end{array}\right]=\left[\frac{F_{2}(\varphi)}{R} \frac{d}{d t}\left\{p\left(t-\frac{R}{C_{\mathrm{S}}}\right)\right\}\right]\left[\begin{array}{c}
\cos \varphi \\
\sin \varphi
\end{array}\right],}
\end{aligned}
$$

where $u_{\mathrm{P}}, u_{\mathrm{S}}, w_{\mathrm{P}}$, and $w_{\mathrm{S}}$ are, respectively, the horizontal and vertical displacements of $\mathrm{P}$ and $\mathrm{S}$ waves, $C_{\mathrm{P}}$ and $C_{\mathrm{S}}$ are, respectively, the travel speeds of $\mathrm{P}$ and $\mathrm{S}$ waves, $R$ is the distance to the source center, $\varphi$ is the angle between the radiation direction and the charge axis, $p(t)$ is the pressure acting on the equivalent column cavity, and $F_{1}(\varphi)$ and $F_{2}(\varphi)$ are the source patterns of $\mathrm{P}$ and $\mathrm{S}$ waves, as expressed in the following equation: 


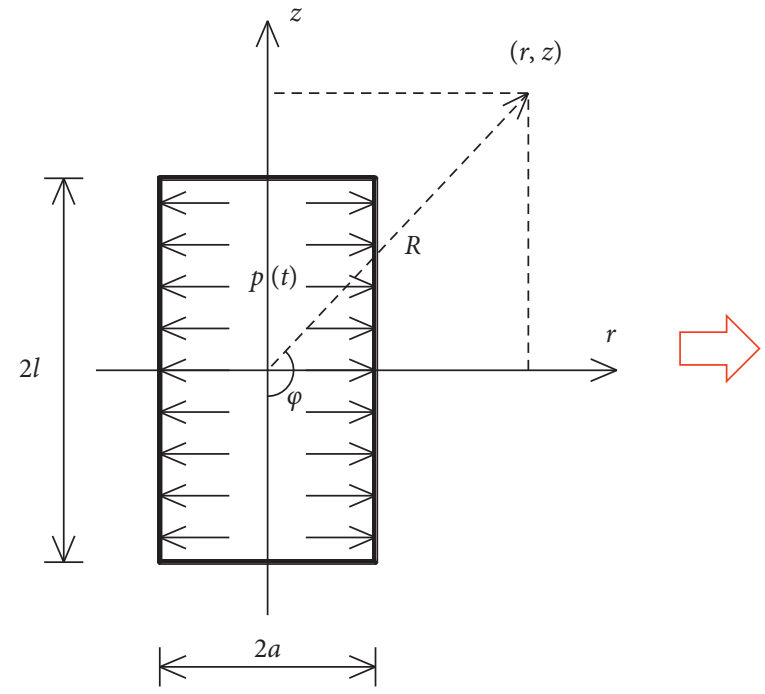

(a)

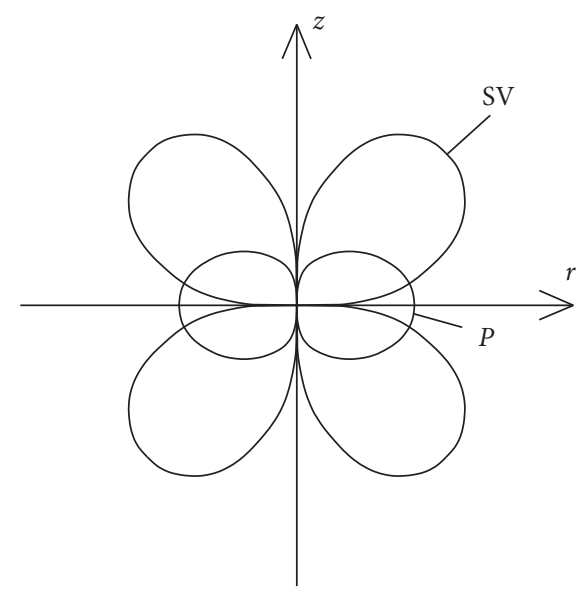

(b)

Figure 5: Illustration of the Heelan radiation. (a) Simplified mechanical model of a short column explosive. (b) Seismic radiation from a short column explosive.

$$
\left\{\begin{array}{l}
F_{1}(\varphi)=\frac{\Delta}{4 \pi \mu C_{\mathrm{P}}}\left(1-2 \cos ^{2} \varphi \frac{C_{\mathrm{S}}^{2}}{C_{\mathrm{P}}^{2}}\right), \\
F_{2}(\varphi)=\frac{\Delta}{4 \pi \mu C_{\mathrm{S}}} \sin 2 \varphi,
\end{array}\right.
$$

where $\Delta$ is the volume of the equivalent column cavity and $\mu$ is the shear modulus.

As mentioned in Section 2, for an extended cylindrical charge, the contribution from every charge element should be delayed according to $\mathrm{VoD}$ and summed along the entire length. Using this technique, and assuming the seed wave of Heelan radiation, Figure 6 and equations (9) (10) provide the computation process of the blast vibration field of an extended cylindrical charge. Equation (9) describes the velocity radiation of the charge element, which is derived by differentiating and summing equations (6) and (7). Then equation (10) gives the blast vibration field of the entire cylindrical charge under bottom initiation ( $A$-initiated). Similarly, the blast vibration field under top initiation ( $B$-initiated), midpoint initiation $(O$ initiated), and two-end initiation ( $A B$-initiated) can also be acquired by changing several positive or negative signs in equation (10).

$$
\begin{aligned}
{\left[\begin{array}{c}
V_{r i} \\
V_{z i}
\end{array}\right]=} & {\left[\frac{F_{1}\left(\varphi_{i}\right)}{R_{i}} \frac{\mathrm{d}}{\mathrm{d} t^{2}}\left\{p\left(t-\frac{(i-1) L}{n D}-\frac{R_{i}}{C_{\mathrm{P}}}\right)\right\}\right]\left[\begin{array}{c}
\sin \varphi_{i} \\
-\cos \varphi_{i}
\end{array}\right] } \\
& +\left[\frac{F_{2}\left(\varphi_{i}\right)}{R_{i}} \frac{\mathrm{d}}{\mathrm{d} t^{2}}\left\{p\left(t-\frac{(i-1) L}{n D}-\frac{R_{i}}{C_{\mathrm{S}}}\right)\right\}\right]\left[\begin{array}{c}
\cos \varphi_{i} \\
\sin \varphi_{i}
\end{array}\right]
\end{aligned}
$$

where $V_{r i}$ and $V_{z i}$ are, respectively, the horizontal and vertical blast vibration velocity of each charge element.

$$
\left\{\begin{array}{l}
\sin \varphi_{i}=\frac{r}{R_{i}}, \\
\cos \varphi_{i}=\frac{z-(i-1 / 2) L / n+L / 2}{R_{i}}, \\
R_{i}=\sqrt{r^{2}+\left(z-\frac{(i-1 / 2) L}{n}+\frac{L}{2}\right)^{2}}, \\
{\left[\begin{array}{l}
V_{r} \\
V_{z}
\end{array}\right]=\sum_{i=1}^{n}\left[\begin{array}{l}
V_{r i} \\
V_{z i}
\end{array}\right]}
\end{array}\right.
$$

In this analysis, the wave shape of the pressure produced by the explosive is described by the following equation and Figure 7, which are based on the experimental data of Grady et al. [32] and Larson [33]:

$$
p(t)=p_{b} e^{t}\left[t^{\kappa}-2 \kappa t^{\kappa-1}+\kappa(\kappa-1) t^{\kappa-2}\right],
$$

where $p_{b}$ is the peak pressure and $\kappa$ depends on the particular explosive used. The parameters of the explosive charge and rock mass are as follows: the explosive density is $1243 \mathrm{~kg} / \mathrm{m}^{3}$, $\mathrm{VoD}$ is $3600 \mathrm{~m} / \mathrm{s}$, the charge length is $3 \mathrm{~m}$, the charge diameter is $32 \mathrm{~mm}$, the rock mass density is $2700 \mathrm{~kg} / \mathrm{m}^{3}$, Young's modulus is $25 \mathrm{GPa}$, and Poisson's ratio is 0.25 . Figure 8 shows the typical velocity waveform computed through the above methodology.

\subsection{Comparison of PPVs under Differing Initiation Locations}

3.2.1. Comparison of PPVs Observed along the Axial Direction. The PPV (peak particle velocity) indictor, as is generally used to evaluate the structural damage, was also 


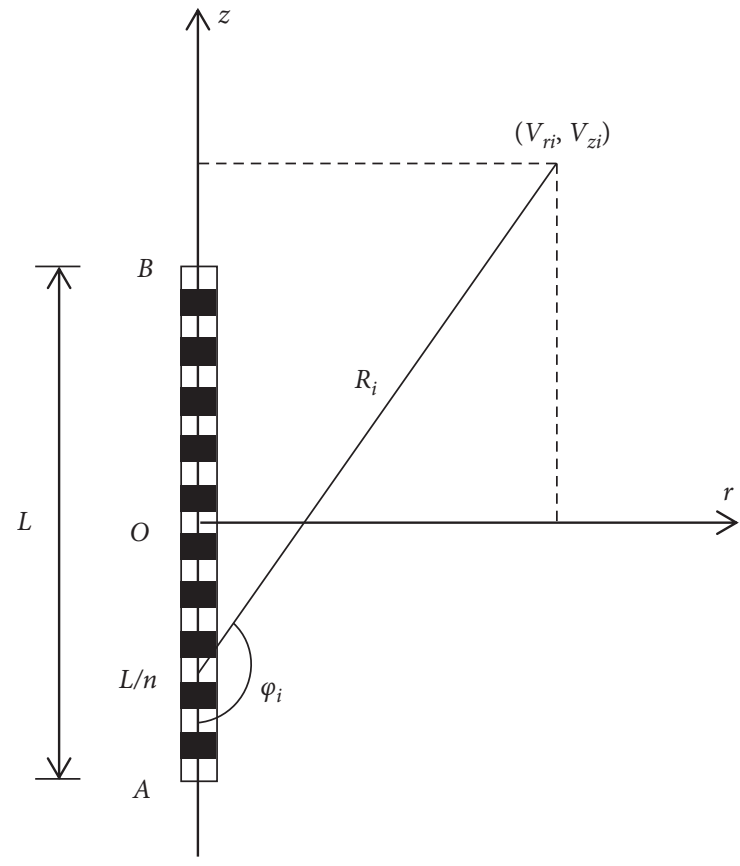

Figure 6: Computation model of the blast vibration field of an extended cylindrical charge.

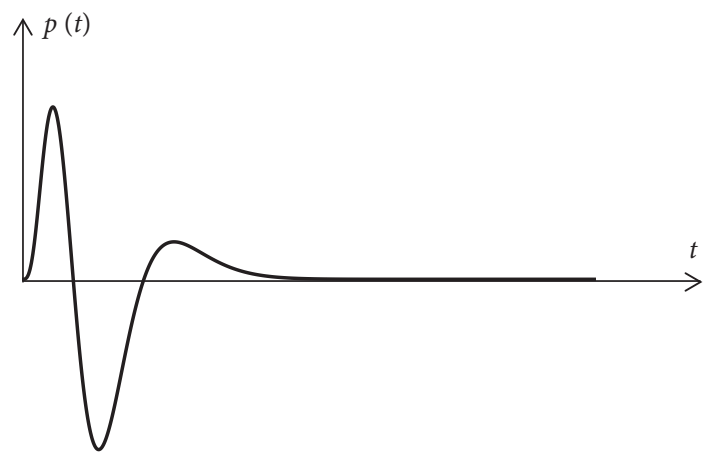

Figure 7: Wave shape of the pressure acting on the equivalent cavity produced by the explosive.

chosen to study the blast vibration field. As shown in Figure 9, Table 1 lists the PPVs observed along the axial direction of the charge. The letters $A, B, O$, and $A B$, respectively, denote the bottom initiation, top initiation, midpoint initiation, and two-end initiation. The vector PPV is the synthesis of the radial and vertical PPVs. Figure 10 also plots the PPV against SD (scaled distance, $\mathrm{m} / \mathrm{kg}^{1 / 2}$ ).

Table 1 and Figure 10 indicate that the PPV under bottom initiation ( $A$-initiated) is the largest, the PPV under top initiation ( $B$-initiated) is the smallest, while the PPVs under midpoint and two-end initiations $(O$-initiated and $A B$-initiated) are approximately equal and embodies as the intermediate level. This is attributed to the phase delay effect of the charge elements. For the bottom initiation, the observation points are located at the forward direction of the detonation wave, so the contributions from the subsequent charge elements become stronger and stronger. But for the top initiation, the wave amplitudes of the subsequent charge

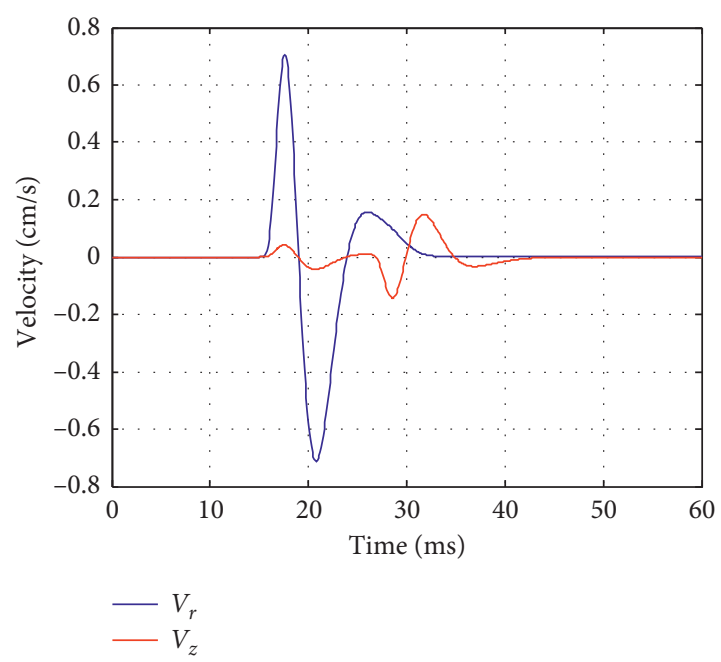

FIgURE 8: Typical blast vibration velocity waveform computed by the seed wave-based superposition model, where $V_{r}$ and $V_{z}$ are, respectively, the horizontal and vertical velocities.

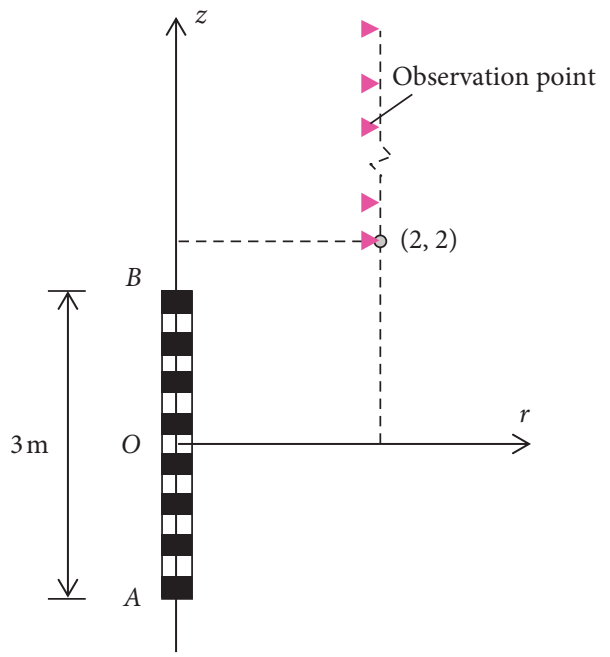

FIgURE 9: Illustration of the observation points along the axial direction of the cylindrical charge.

elements decrease with the detonation wave propagating downwards. Therefore, for the observation points located at the top side, the PPV under bottom initiation is larger than that under top initiation.

Figure 11 illustrates the PPV difference ratio $\eta$ of bottom and top initiations. Based on the vector PPV, the PPV difference ratio $\eta$ is defined by the following equation hereinafter:

$$
\eta=\frac{v \mathbf{P} \mathbf{P V} \mathbf{V}_{A}-v \mathbf{P P \mathbf { V } _ { B }}}{v \mathbf{P P V}} \times 100 \%,
$$

where $v \mathbf{P P V} \mathbf{V}_{A}$ and $\nu \mathbf{P P V} \mathbf{V}_{B}$ are, respectively, the vector $\mathbf{P P V}$ under bottom and top initiations. Figure 11 indicates that the PPV difference ratio $\eta$ is about $8 \% \sim 13 \%$ and decreases with $\mathrm{SD}$. In other words, the initiation location mainly affects the blast vibration field near the explosive charge, and its effect might be ignored if the observation point is enough far. 
TABle 1: Computational PPVs observed along the axial direction of the cylindrical charge.

\begin{tabular}{lcccccccccccc}
\hline$z(\mathrm{~m})$ & \multicolumn{3}{c}{ Radial PPV $(\mathrm{cm} / \mathrm{s})$} & \multicolumn{3}{c}{ Vertical PPV $(\mathrm{cm} / \mathrm{s})$} & \multicolumn{4}{c}{ Vector PPV $(\mathrm{cm} / \mathrm{s})$} \\
& $A$ & $B$ & $O$ & $A B$ & $A$ & $B$ & $O$ & $A B$ & $A$ & $B$ & $O$ \\
\hline 2 & 19.63 & 17.9 & 18.96 & 18.96 & 11.03 & 8.85 & 10.15 & 10.01 & 22.52 & 19.97 & 21.51 & 21.44 \\
5 & 8.58 & 7.66 & 8.23 & 8.18 & 3.38 & 2.89 & 3.04 & 2.95 & 9.22 & 8.19 & 8.77 & 8.70 \\
10 & 2.42 & 2.15 & 2.31 & 2.31 & 1.58 & 1.37 & 1.50 & 1.49 & 2.89 & 2.55 & 2.75 & 2.75 \\
15 & 1.07 & 0.95 & 1.02 & 1.02 & 0.96 & 0.88 & 0.94 & 0.93 & 1.44 & 1.29 & 1.39 & 1.38 \\
25 & 0.39 & 0.35 & 0.37 & 0.38 & 0.49 & 0.46 & 0.48 & 0.48 & 0.63 & 0.58 & 0.61 \\
40 & 0.16 & 0.14 & 0.15 & 0.15 & 0.31 & 0.29 & 0.30 & 0.30 & 0.35 & 0.32 & 0.34 \\
\hline
\end{tabular}

The letters $A, B, O$, and $A B$, respectively, denote bottom initiation, top initiation, midpoint initiation, and two-end initiation. The vector PPV denotes the synthesis of the radial and vertical PPVs.

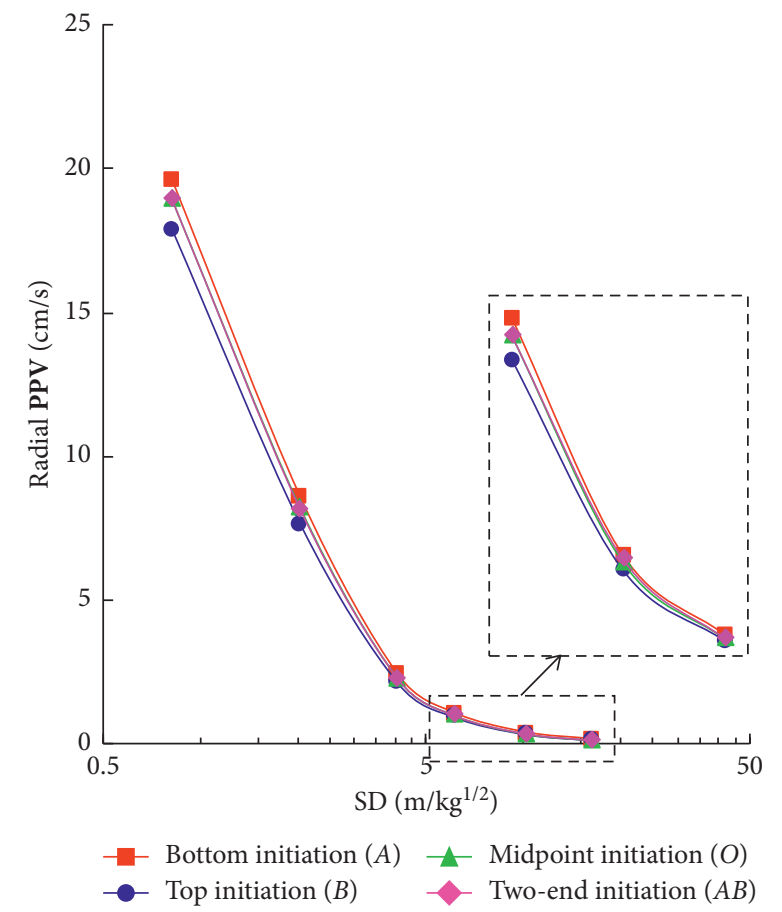

(a)

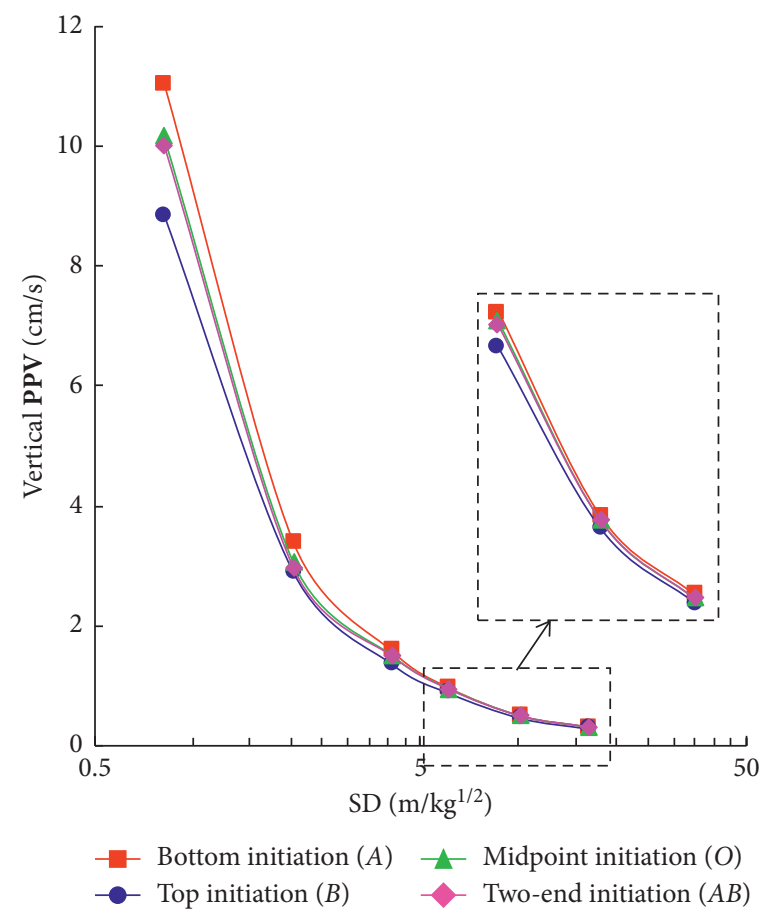

(b)

Figure 10: Comparison of PPVs observed along the axial direction of the cylindrical charge. (a) Radial PPV. (b) Vertical PPV.

3.2.2. Comparison of PPVs Observed along the Radial Direction. Table 2 lists the PPVs observed along the radial direction of the charge (Figure 12), and Figure 13 also plots the PPV against SD. Table 2 and Figure 13 indicate that the PPV under bottom initiation is larger than that under top initiation. However, the PPVs under midpoint and two-end initiations will exceed that under bottom initiation if $r$ increases. In fact, two charge elements contribute to the superposition of the blast vibration field under midpoint and two-end initiations because the detonation wave simultaneously propagates upwards and downwards from the midpoint or two ends of the explosive charge. Thus, the vibration amplitude of the bidirectional superposition (midpoint or two-end initiation) is larger than that of the unidirectional superposition (bottom or top initiation), irrespective of the length effect of the explosive charge.

It is interesting that the vertical PPV does not strictly decrease with $r$ but increases to the maximum at a certain location. This might be caused by the channeled radiation of $\mathrm{P}$ and $\mathrm{S}$ waves (Figure 5). But it merely affects the local amplitude and cannot vary the global attenuation of distance. Figure 14 plots the PPV difference ration $\eta$ observed along the radial direction of the cylindrical charge. It also indicates that the PPV difference ration $\eta$ decreases with SD and tends to zero if SD exceeds $7 \mathrm{~m} /$ $\mathrm{kg}^{1 / 2}(r \approx 30 \mathrm{~m})$.

3.3. Sensitivity Analysis of the Parameters of the Explosive Charge. As aforementioned, the inherent mechanism lies in the geometrical characteristic and finite $\mathrm{VoD}$ of the explosive charge. Thus, the phase delay effect would disappear, if the length-to-diameter ratio of the explosive charge is negligible, or the detonation velocity is infinitely high. In this section, the sensitivity of the charge length $L$ and the detonation velocity $D$ affecting the blast vibration 


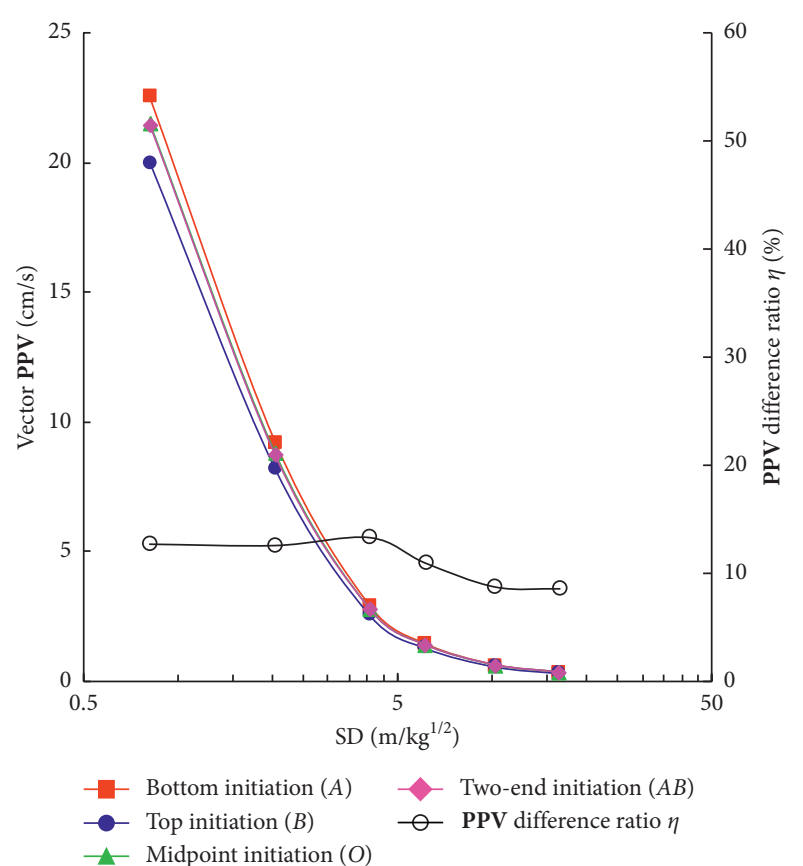

Figure 11: Illustration of the PPV difference ratio $\eta$ observed along the axial direction of the cylindrical charge.

field were analyzed by comparing the PPVs under bottom and top initiations, as illustrated in Figure 15. It indicates that the PPV difference ratio $\eta$ increases with the charge length $L$ and decreases with the detonation velocity $D$. This demonstrates that the effect of the initiation location on the blast vibration field is sensitive to the charge length $L$ and the detonation velocity $D$. The initiation location might play an important role in the blast vibration field of the deep-hole blasting. But the phase delay effect would be greatly discounted if high-energy explosive with large VoD is used.

\section{Experimental Validation of the Effect of the Initiation Location on Blast Vibration}

\subsection{Single-Hole Blasting Experiment in Bai-He-Tan Hydropower Station}

4.1.1. Blast Design. Bai-he-tan Hydropower Station, with the total capacity of $16,000 \mathrm{MW}$, is at present the largest one under construction. It is the second step of the four hydropower stations (Wu-dong-de, Bai-he-tan, Xi-luo-du, and Xiang-jia-ba) in the downstream of Jin-sha River and is located at the border of Ningnan country of Sichuan province and Qiaojia country of Yunnan province in China. The single-hole blasting experiment was conducted during the foundation excavation of the plunge pool at Bai-he-tan Hydropower Station.

As shown in Figure 16, four vertical blastholes were, respectively, placed at the square corners. The drill and blast parameters are listed in Table 3. All the blastholes were fired in the same initiation network (Figure 17(a)), and the inner-hole nonelectric millisecond (MS) detonator was used to separate each shot. The delay time was, respectively, MS1 (0 ms), MS5 (110 ms), MS9 (310 ms), and MS13 (650 ms). To study the effect of the initiation location, blastholes I and II were top initiated, while blastholes III and IV were bottom initiated, as illustrated in Figure 18. It needs to be pointed that the shock wave-reflecting blocks were placed at the bottom of blastholes I and III. The additional design is beyond the scope of this study, but it does not affect the contrast groups, i.e., blastholes I versus III and blastholes II versus IV. As shown in Figure 17(b), three uniaxial vibration sensors were installed within the monitoring hole, and they were, respectively, $1.0 \mathrm{~m}, 1.5 \mathrm{~m}$, and $2.0 \mathrm{~m}$ below the blasthole bottom. Besides, one triaxial vibration sensor was placed at the ground surface, and it was $70 \mathrm{~m}$ away from the square center (Figure 16).

4.1.2. Test Results. Figure 19 presents the pictures of rock mass at the ground surface after blasting. It indicates that the behaviors of the rock mass of the four blastholes are very different. For blastholes I and II (top initiated), only a few blasting cracks were generated and almost no rock fragments were thrown outwards. While for blastholes III and IV (bottom initiated), small blasting crater was formed and some rock fragments were thrown outwards. Moreover, the color of the rock mass of blastholes III and IV is a little darker than those of blastholes I and II. This is because that the rock mass with higher humidity below the ground surface was lifted out by the upward transmitting explosion energy of blastholes III and IV. Apparently, more explosion energy is transmitted to the ground surface if the explosive charge is bottom initiated. The behavior of rock mass after blasting demonstrates that the explosion energy is preferentially transmitted to the forward direction of the detonation wave.

Figure 20 plots the typical blast vibration waveform measured by using the \#2 vibration sensor. Four blast signals are separated in the time axis, and the arrival time of each signal is coincident with the delay detonator. They, respectively, stand for the blast vibrations of blastholes I IV. Table 4 lists the measured PPVs of the four blastholes. Figures 21 and 22 also illustrate the comparison of PPVs under differing initiation locations in the form of histogram.

The test results indicate that the vibration amplitude is associated with the relative orientation between the observation point and the detonation wave. For the vibration sensors \#1 \#3, which are located below the blasthole bottom (bottom side of the explosive charge), the PPV under top initiation is much larger than that under bottom initiation (Figure 21). However, for the vibration sensor \#4, as is located at the ground surface (top side of the explosive charge), the PPV under top initiation is much smaller than that under bottom initiation (Figure 22). Figures 21 and 22 verify that the vibration amplitude at the forward direction of the detonation wave is larger than that at the backward direction. This is in accordance with the energy distribution and phase delay 
TABle 2: Computational PPVs observed along the radial direction of the cylindrical charge.

\begin{tabular}{|c|c|c|c|c|c|c|c|c|c|c|c|c|}
\hline \multirow{2}{*}{$r(\mathrm{~m})$} & \multicolumn{4}{|c|}{ Radial PPV (cm/s) } & \multicolumn{4}{|c|}{ Vertical PPV $(\mathrm{cm} / \mathrm{s})$} & \multicolumn{4}{|c|}{ Vector PPV $(\mathrm{cm} / \mathrm{s})$} \\
\hline & $A$ & $B$ & $O$ & $A B$ & $A$ & $B$ & $O$ & $A B$ & $A$ & $B$ & $O$ & $A B$ \\
\hline 2 & 16.15 & 14.58 & 15.58 & 15.49 & 7.59 & 5.55 & 6.87 & 6.53 & 17.84 & 15.60 & 17.03 & 16.81 \\
\hline 5 & 8.09 & 7.36 & 7.78 & 7.82 & 7.75 & 6.66 & 7.35 & 7.43 & 11.20 & 9.93 & 10.70 & 10.79 \\
\hline 10 & 3.11 & 2.96 & 3.12 & 3.12 & 3.80 & 3.54 & 3.74 & 3.78 & 4.91 & 4.61 & 4.87 & 4.90 \\
\hline 15 & 2.23 & 2.15 & 2.25 & 2.26 & 1.96 & 1.87 & 1.95 & 1.97 & 2.97 & 2.85 & 2.98 & 3.00 \\
\hline 20 & 1.71 & 1.68 & 1.74 & 1.75 & 1.06 & 1.03 & 1.07 & 1.07 & 2.01 & 1.97 & 2.04 & 2.05 \\
\hline 30 & 1.17 & 1.17 & 1.19 & 1.19 & 0.43 & 0.42 & 0.43 & 0.43 & 1.25 & 1.24 & 1.27 & 1.27 \\
\hline 40 & 0.89 & 0.89 & 0.90 & 0.90 & 0.24 & 0.24 & 0.24 & 0.24 & 0.92 & 0.92 & 0.93 & 0.93 \\
\hline 50 & 0.71 & 0.71 & 0.72 & 0.72 & 0.15 & 0.15 & 0.15 & 0.15 & 0.73 & 0.73 & 0.74 & 0.74 \\
\hline 60 & 0.59 & 0.59 & 0.60 & 0.60 & 0.10 & 0.10 & 0.10 & 0.10 & 0.60 & 0.60 & 0.61 & 0.61 \\
\hline 70 & 0.51 & 0.51 & 0.52 & 0.52 & 0.08 & 0.08 & 0.08 & 0.08 & 0.52 & 0.52 & 0.53 & 0.53 \\
\hline 80 & 0.45 & 0.45 & 0.45 & 0.45 & 0.06 & 0.06 & 0.06 & 0.06 & 0.45 & 0.45 & 0.45 & 0.45 \\
\hline 100 & 0.40 & 0.40 & 0.40 & 0.40 & 0.05 & 0.05 & 0.05 & 0.05 & 0.40 & 0.40 & 0.40 & 0.40 \\
\hline
\end{tabular}

The letters $A, B, O$, and $A B$, respectively, denote bottom initiation, top initiation, midpoint initiation, and two-end initiation. The vector PPV denotes the synthesis of the radial and vertical PPVs.

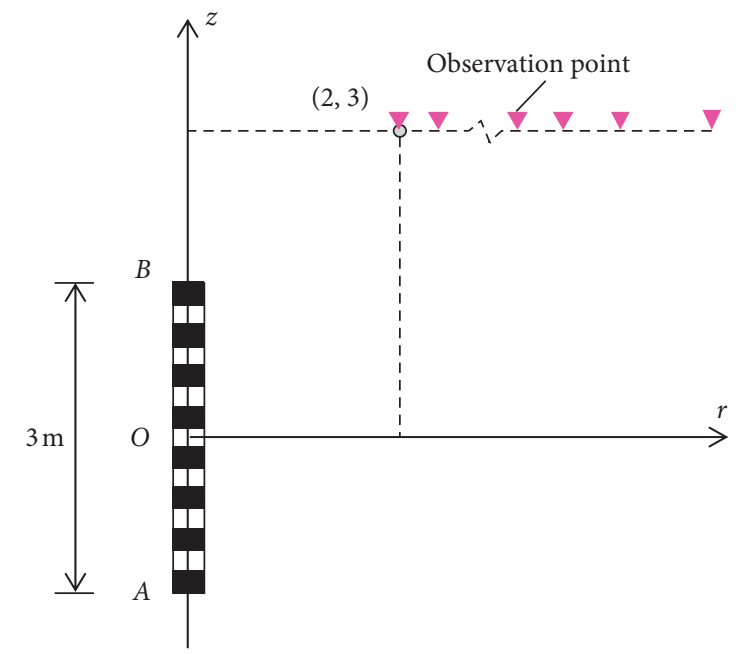

Figure 12: Illustration of the observation points along the radial direction of the cylindrical charge.

effects of the cylindrical charge, as was mentioned in Sections 2 and 3 . It needs to be clarified that the blast vibration induced by blasthole IV at the ground surface (\#4) is covered by other blasting operations, so its PPV is not included in Table 4 and Figure 22.

\subsection{Production Blasting Experiment in Zhou-Shan Petrochemical Base}

4.2.1. Blast Design. Zhou-shan Petrochemical Base is located in the Da-yu-shan and Xiao-yu-shan districts of Zhou-shan islands of Zhejiang province in China. It consists of 4,100 hectares of the land reclamation and is an integrated refining and chemical petrochemical base. The blasting experiment was conducted during the production excavation of mountains. Figure 23 presents the pictures of the experiment area.

As illustrated in Figure 24, this production blasting includes 7 rows of 129 blastholes. Six ground vibration sensors were placed at the lateral side of the blasting area.
The drill and blast parameters are listed in Table 5. All the blastholes were fired in the same initiation network, where the interhole and inter-row detonators were, respectively, MS3 (50 ms) and MS5 (110 ms). The explosive within each blasthole was fired by the detonator MS10 $(380 \mathrm{~ms})$. To further study the effect of the initiation location, the last two single blastholes $\mathrm{S} 1$ and $\mathrm{S} 2$ were separated from the initiation network by the interhole detonator MS $9(310 \mathrm{~ms})$. The charging structures of blastholes S1 and S2 are plotted in Figure 25, where the blasthole S1 is top initiated and the blasthole S2 is bottom initiated. The distance $R$ of the monitoring points to the blastholes S1 and S2 varies from $26.0 \mathrm{~m}$ to $86.4 \mathrm{~m}$.

4.2.2. Test Results. As plotted in Figure 26, the blast vibration waveforms of the production blastholes overlap with each other, while the blast vibrations of blastholes S1 and S2 are thoroughly separated at the time axis. Table 6 lists the measured PPVs of blastholes S1 and S2, where the vector PPV is the synthesis of the radial, tangential, and vertical PPVs. Figure 27 plots the fitted curves of the PPV against SD by using the following equation:

$$
\mathbf{P P V}=K(S D)^{-\alpha},
$$

where $K$ and $\alpha$ are the attenuation factors that are associated with the on-site geological conditions.

Table 6 and Figure 27 also verify that the vibration amplitude at the forward direction of the detonation wave is larger than that at the backward direction. As the ground vibration sensors are located at the top side of the explosive charge, the PPVs of the blasthole S2 (bottom initiated) all larger than those of the blasthole S1 (top initiated). Figure 28 plots the PPV difference ratio $\eta$ of blastholes S1 and S2 against SD. It indicates that the effect of the initiation location is ignorable if SD is large enough because the PPV difference ratio $\eta$ gradually decreases with SD. The production experiment again provides a solid evidence for the effect of the initiation location on blast vibration field. 


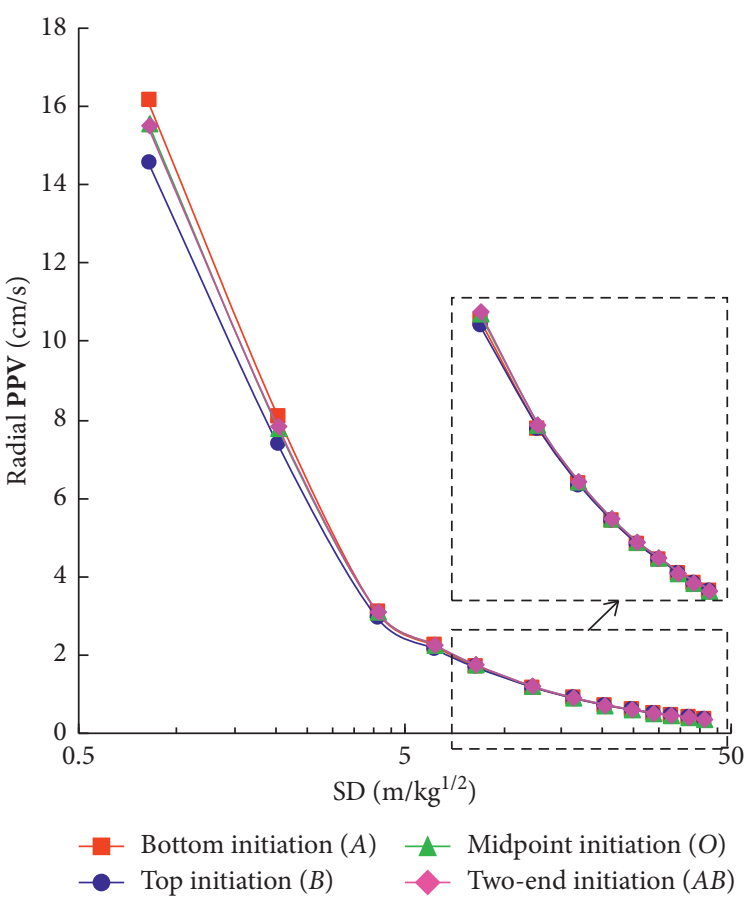

(a)

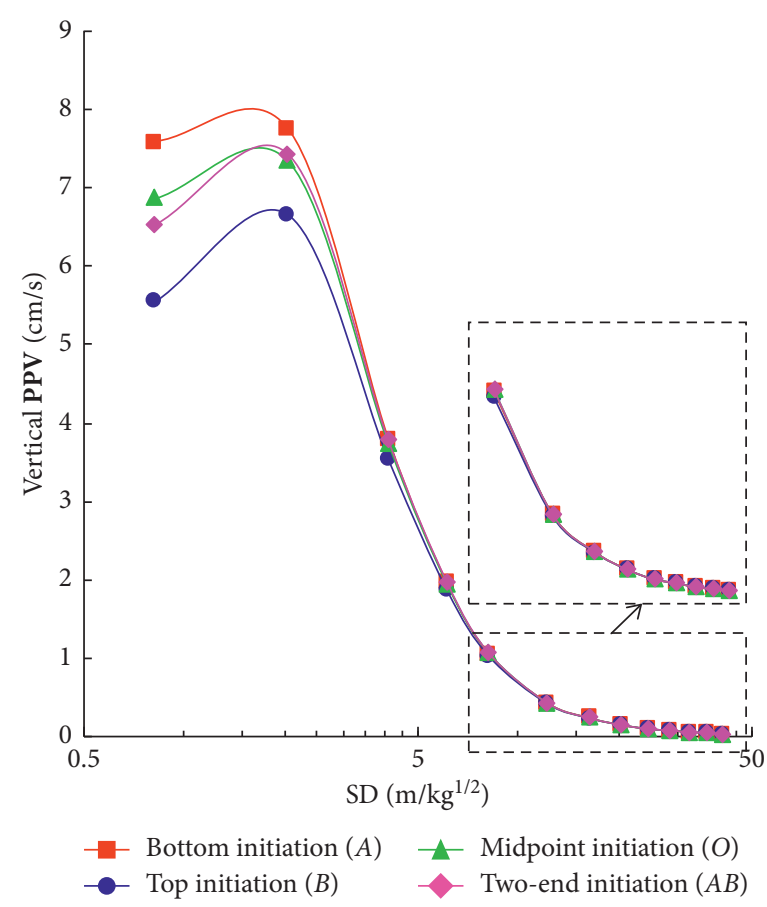

(b)

Figure 13: Comparison of PPVs observed along the radial direction of the cylindrical charge. (a) Radial PPV. (b) Vertical PPV.

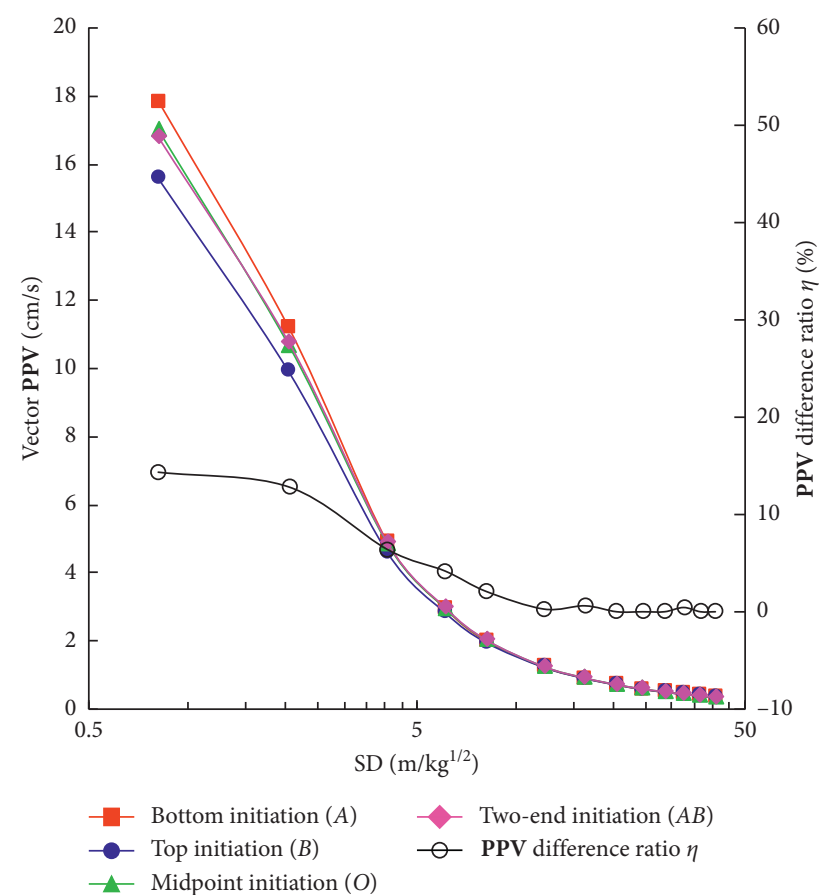

FIGURE 14: Illustration of the PPV difference ratio $\eta$ observed along the radial direction of the cylindrical charge.

\section{Discussion}

The computational and experimental results both indicate that the initiation location plays an important role in the blast vibration field of the cylindrical charge. Due to the large length-to-diameter ratio and finite $\mathrm{VoD}$ characteristics, the detonation reaction of the cylindrical charge usually begins at the initiation point and then propagates to the entire length, as is the so-called time and directional effects. Therefore, the underlying mechanism of the initiation location lies in the geometrical and finite VoD characteristics of the explosive charge. As mentioned in Section 2, it can be interpreted as the combined results of the energy distribution effect along the detonation direction and the phase delay effect of the charge elements.

For the energy distribution effect, the behavior of the rock mass at the ground surface in the single-hole blasting experiment demonstrated that the explosion energy is preferentially transmitted to the forward direction of the detonation wave. However, the phase delay effect, causing the nonuniform distribution of the blast vibration filed, was verified by the seed wave-based computational model. It needs to be clarified that the computational model merely focuses on the phase delay effect, irrespective of the energy distribution effect. As a result, the PPV difference ratio $\eta$ acquired from the computational results (Figures 11 and 14) is relative smaller than that acquired from the experimental results (Figures 11, 14, and 28). Obviously, the energy distribution effect and the phase delay effect are not independent, and they jointly act on the blast vibration field.

In addition, the effect of the initiation location is sensitive to the parameters of the explosive charge, especially for the charge length $L$ and the detonation velocity $D$ (Figure 15). This is also attributed to the underlying mechanism that the significant time and directional effects is usually witnessed by the explosive charge with large length and small 


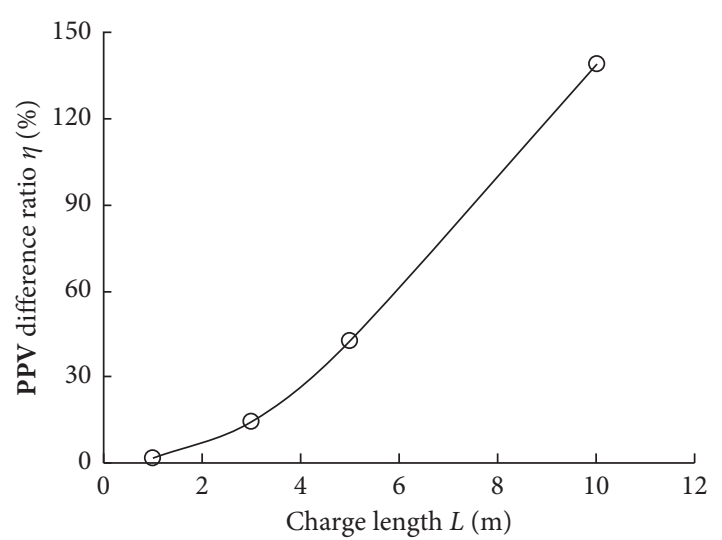

(a)

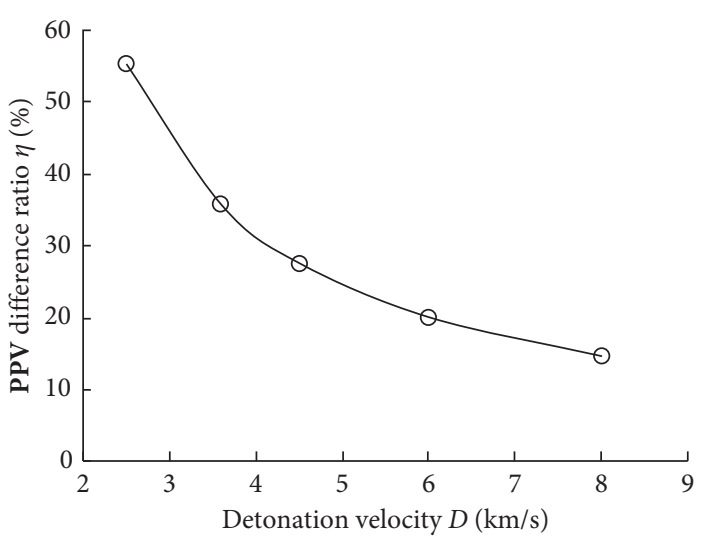

(b)

FIGURE 15: Sensitivity of the charge length $L$ and the detonation velocity $D$ affecting the blast vibration field. PPV difference ratio $\eta$ against (a) the charge length $L$ and (b) the detonation velocity $D$.

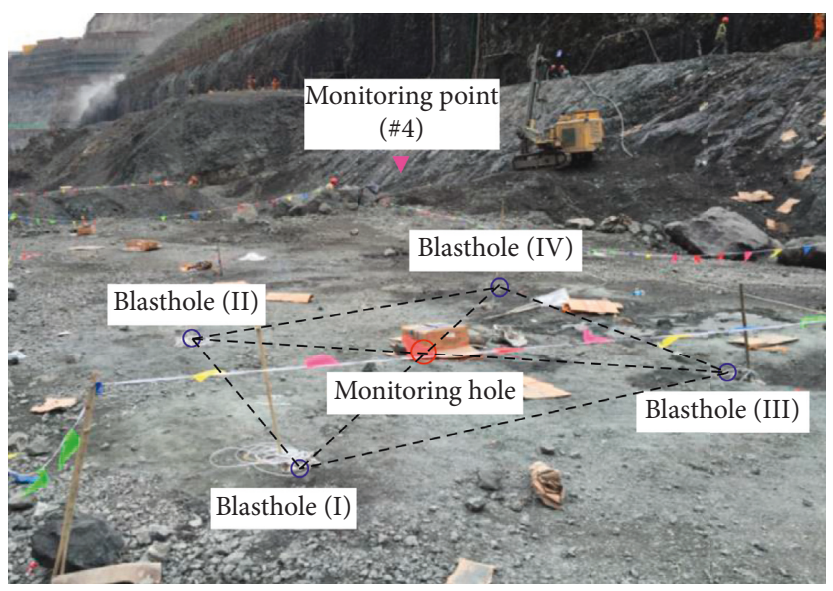

FIGURE 16: On-site layout of blastholes in the single-hole blasting experiment.

TABLE 3: Drill and blast parameters in the single-hole blasting experiment.

\begin{tabular}{lccccc}
\hline Hole diameter $(\mathrm{mm})$ & Hole depth $(\mathrm{m})$ & Spacing $(\mathrm{m})$ & Charge diameter $(\mathrm{mm})$ & Charge length $(\mathrm{m})$ & Charge weight $(\mathrm{kg})$ \\
\hline $100 \mathrm{~mm}$ & $6.0 \mathrm{~m}$ & $3.5 \mathrm{~m}$ & $32 \mathrm{~mm}$ & $4.5 \mathrm{~m}$ & $4.5 \mathrm{~kg}$ \\
\hline
\end{tabular}
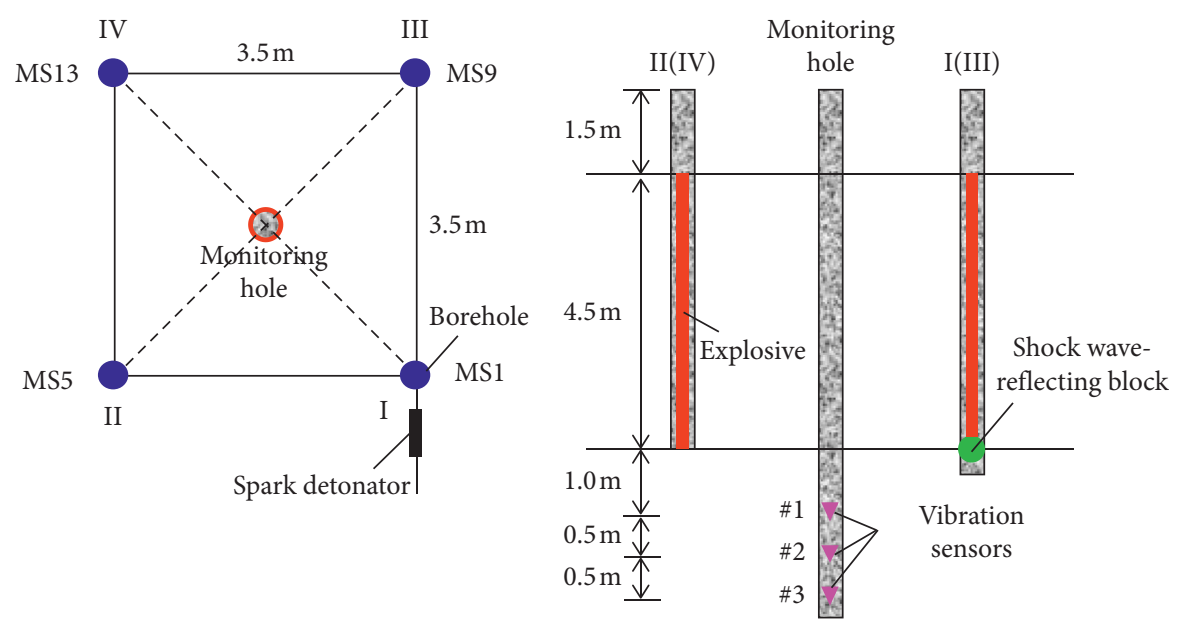

(a)

(b)

FIgURe 17: Arrangement of blastholes and vibration sensors in the single-hole blasting experiment. (a) Plan view of blastholes. (b) Cutaway view of blastholes. 


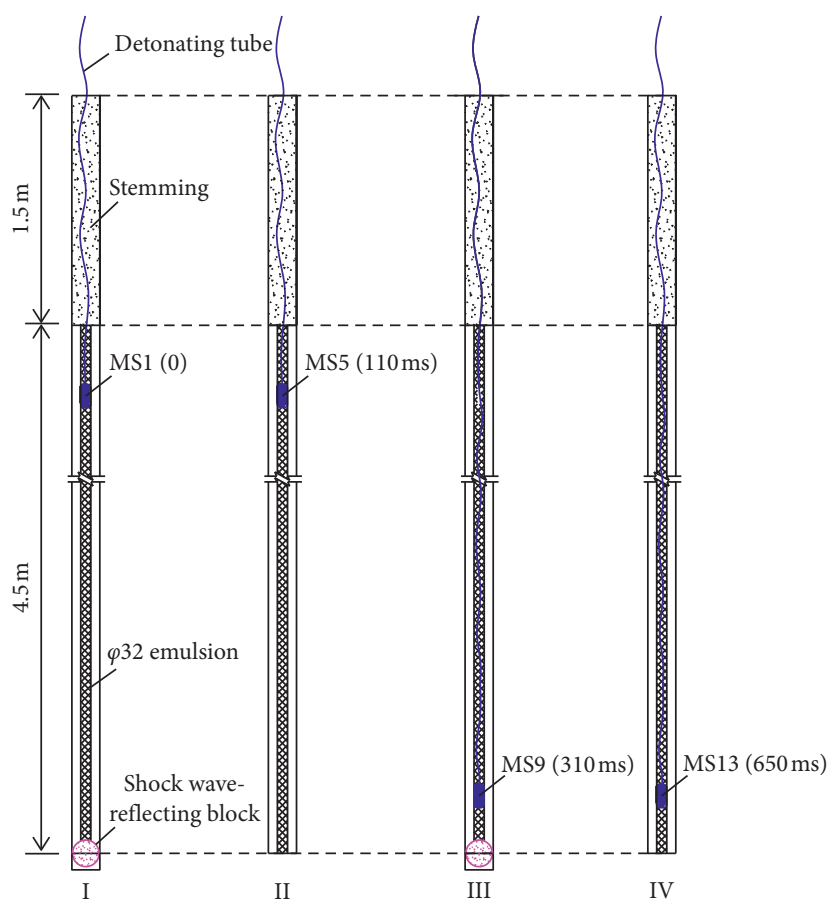

FIGURE 18: Charging structures in the single-hole blasting experiment.
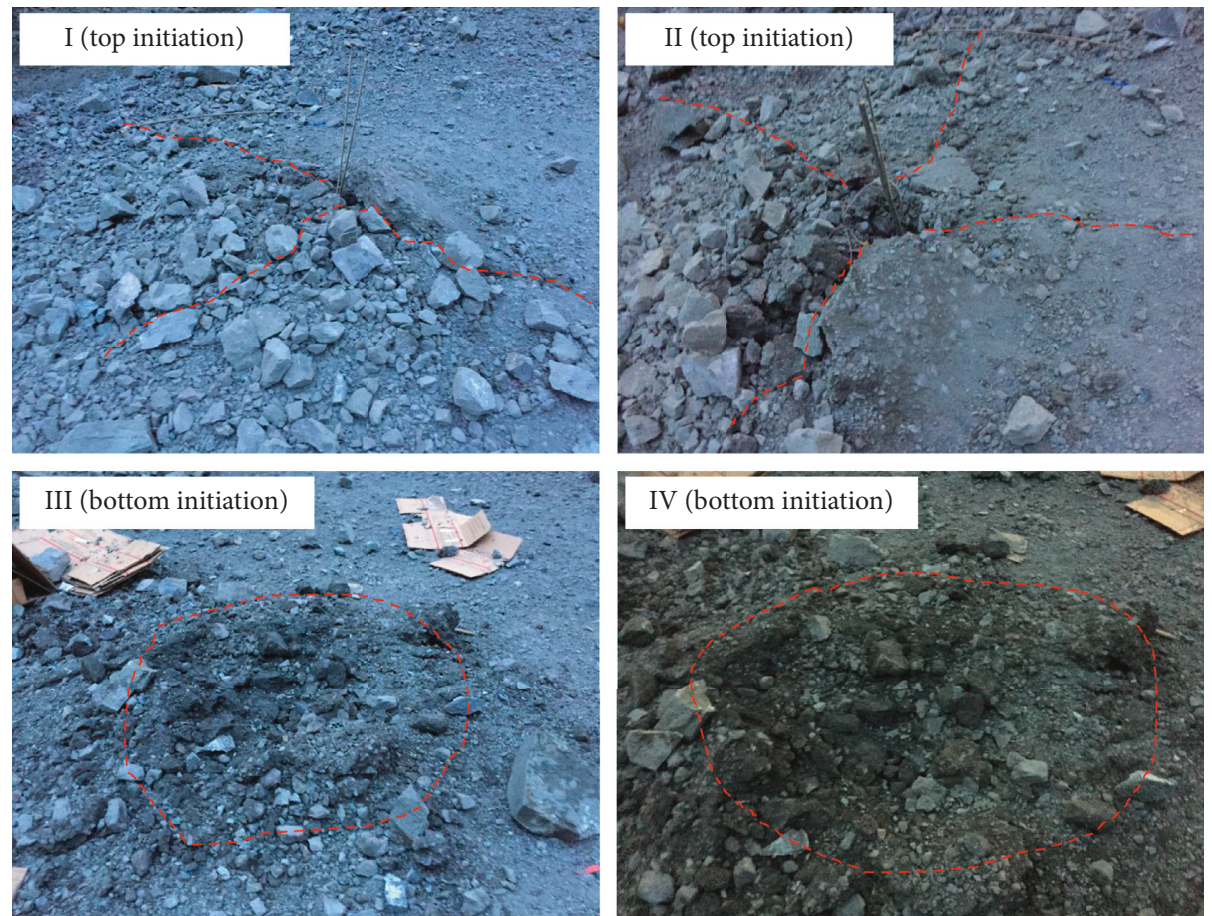

FIGURE 19: Pictures of rock mass after blasting in the single-hole blasting experiment.

detonation velocity. Figures 11, 14, and 28 all indicate that the PPV difference ratio $\eta$ decreases with distance. In other words, the effect of the initiation location can be ignored if the observation point is far enough, which obeys Saint Venant's principle.

\section{Conclusions}

This paper aims to reveal the effect of the initiation location on blast vibration field of the cylindrical charge and its acting mechanism so as to better control the blast vibration 


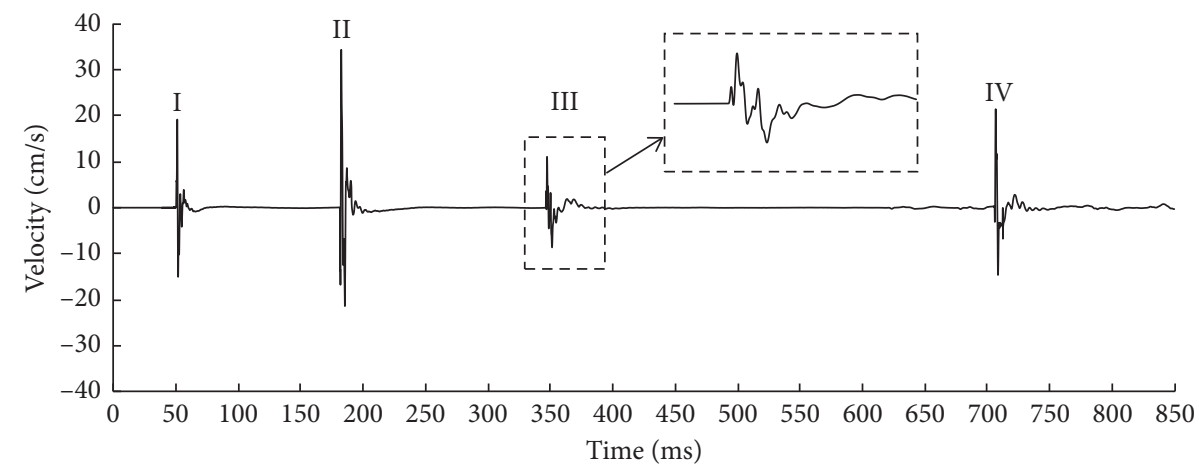

Figure 20: Typical blast vibration waveform in the single-hole blasting experiment (\#2).

Table 4: Measured PPVs in the single-hole blasting experiment.

\begin{tabular}{lcccc}
\hline Sensor no. & & & PPV $(\mathrm{cm} / \mathrm{s})$ & \\
\\
\hline$\# 1$ & Blasthole I & Blasthole II & Blasthole III & Blasthole IV \\
$\# 2$ & 18.37 & 32.50 & 14.51 & - \\
$\# 3$ & 19.21 & 34.40 & 11.09 & 21.47 \\
$\# 4$ & 19.33 & 27.55 & 7.92 & 14.07 \\
Radial & & & 0.27 & - \\
Tangential & 0.27 & 0.40 & 0.13 & - \\
Vertical & 0.13 & 0.20 & 0.25 & - \\
\hline
\end{tabular}

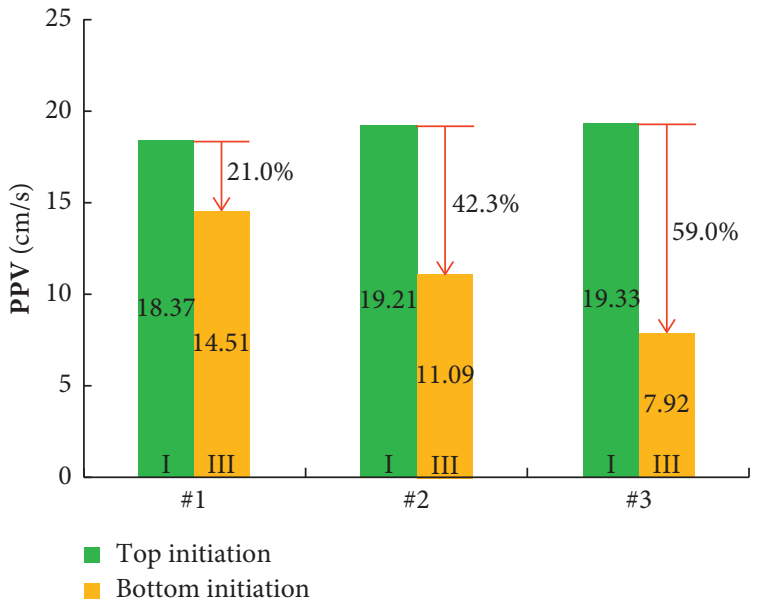

(a)

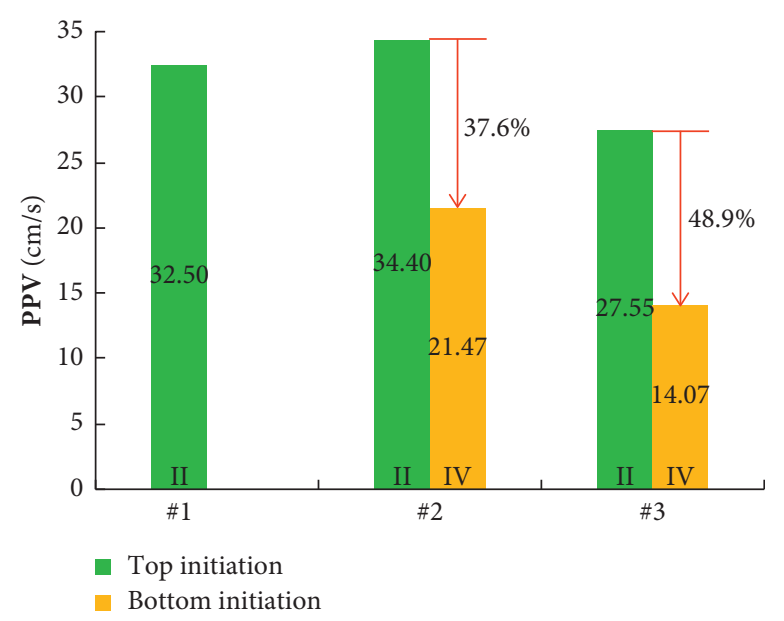

(b)

Figure 21: Comparison of PPVs measured below the blasthole bottom (\#1 \#3) in the single-hole blasting experiment. PPVs induced by blastholes (a) with shock wave-reflecting block and (b) without shock wave-reflecting block.

induced by the widely used drill and blast. The following conclusions are observed:

(1) The underlying effect of the initiation location is caused by the geometrical characteristic (large length-to-diameter ratio) and finite $\mathrm{VoD}$ of the explosive charge. It can be regarded as the combined results of the energy distribution and phase delay effects of the column explosive source.

(2) The theoretical analysis and experimental results both demonstrate that the explosion energy is preferentially transmitted to the forward direction of the detonation wave. Besides, the computational and experimental results verify that the vibration amplitude at the forward direction of the detonation wave is larger than that at the backward direction. The production blasting experiment indicates that the ground PPV under bottom initiation is $61.3 \%$ 211.7\% larger than that under top initiation.

(3) The effect of the initiation location is sensitive to the charge length $L$ and the detonation velocity $D$. 


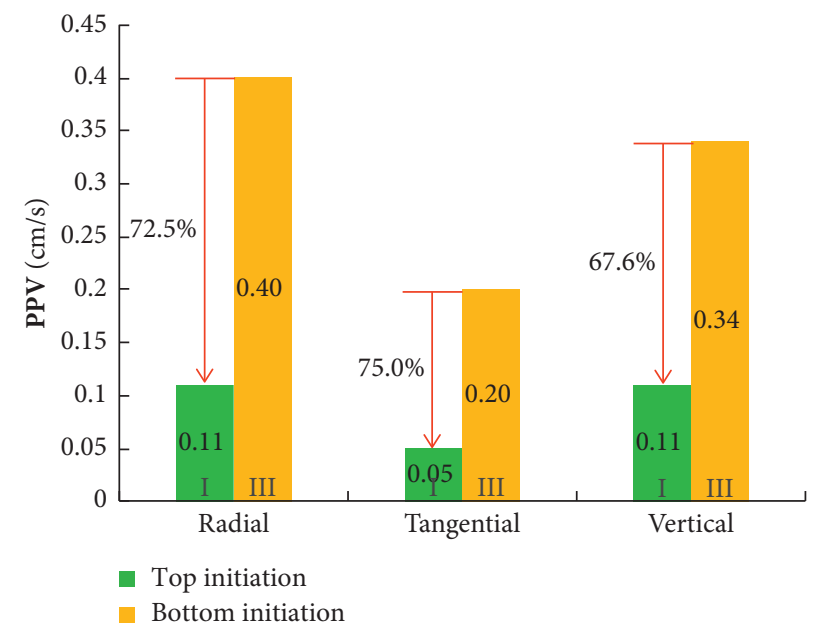

FIgure 22: Comparison of PPVs measured at the ground surface (\#4) in the single-hole blasting experiment.

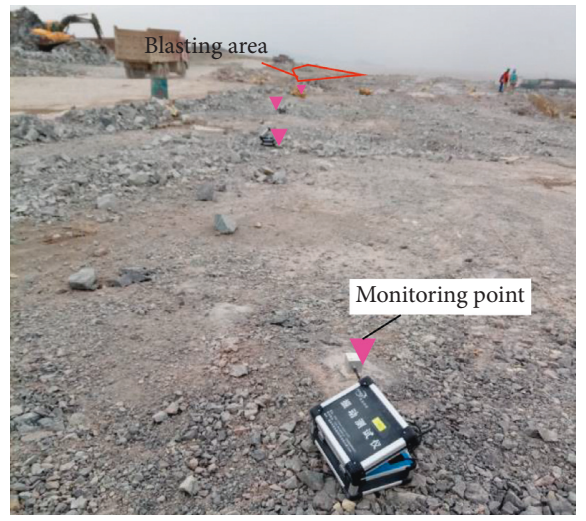

(a)

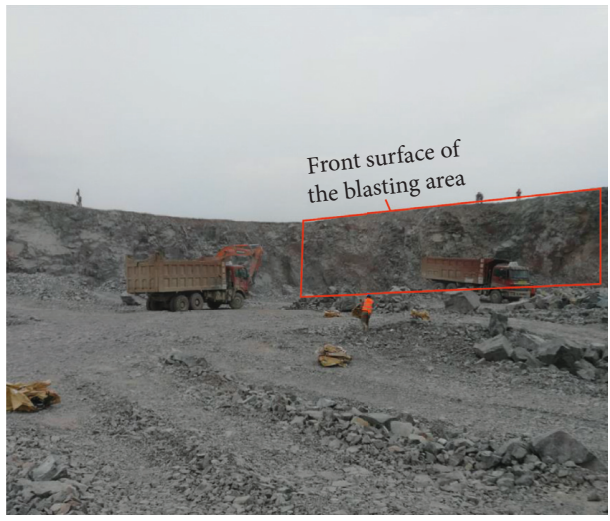

(b)

Figure 23: Pictures of the experiment area in the production blasting. (a) Bird view of the blasting area. (b) Front view of the blasting area.

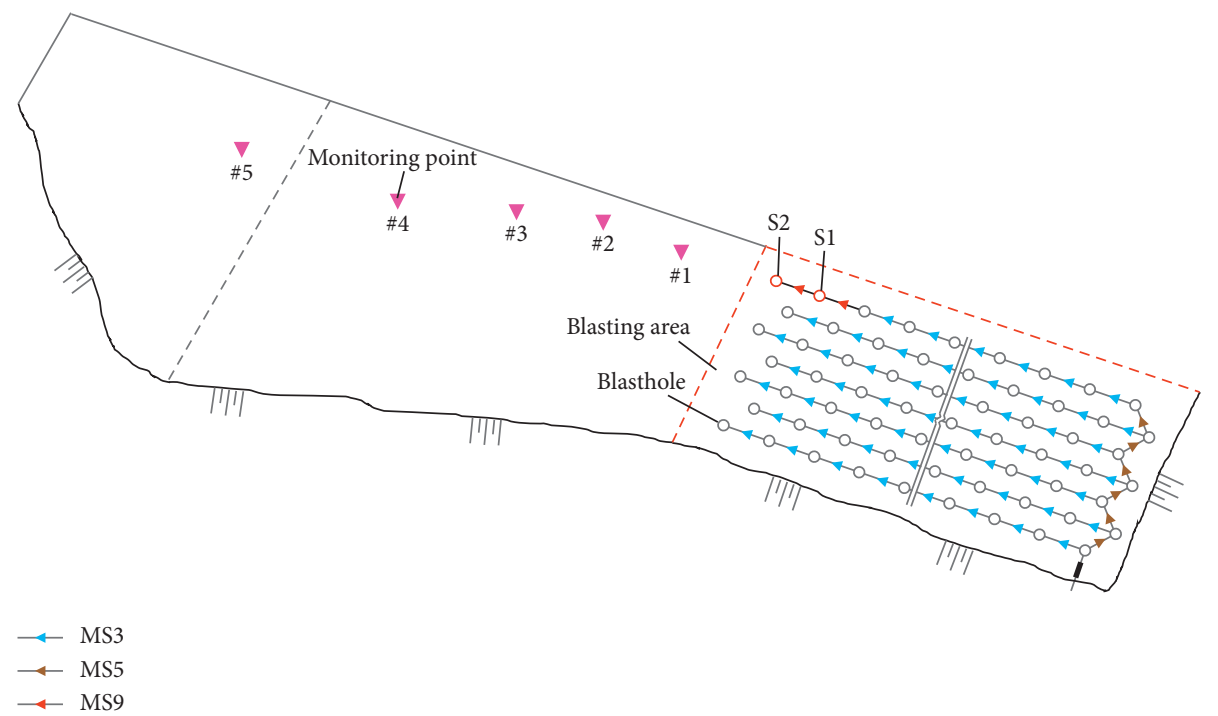

FIGURE 24: Layout of blastholes and vibration monitoring points in the production blasting experiment. 
TABLE 5: Drill and blast parameters in the production blasting experiment.

\begin{tabular}{lccccccc}
\hline Blasthole type & $\begin{array}{c}\text { Hole diameter } \\
(\mathrm{mm})\end{array}$ & $\begin{array}{c}\text { Hole depth } \\
(\mathrm{m})\end{array}$ & $\begin{array}{c}\text { Burden } \\
(\mathrm{m})\end{array}$ & $\begin{array}{c}\text { Spacing } \\
(\mathrm{m})\end{array}$ & $\begin{array}{c}\text { Charge diameter } \\
(\mathrm{mm})\end{array}$ & $\begin{array}{c}\text { Charge weight } \\
(\mathrm{kg})\end{array}$ & $\begin{array}{c}\text { Stemming length } \\
(\mathrm{m})\end{array}$ \\
\hline $\begin{array}{l}\text { Production } \\
\text { holes }\end{array}$ & 115 & $9.3 \sim 14.9$ & 3.5 & $5.0 \sim 6.0$ & 90 & $48 \sim 84$ & $4.5 \sim 5.5$ \\
Single holes & 115 & 15.0 & - & - & 90 & 72 & 5.0 \\
\hline
\end{tabular}

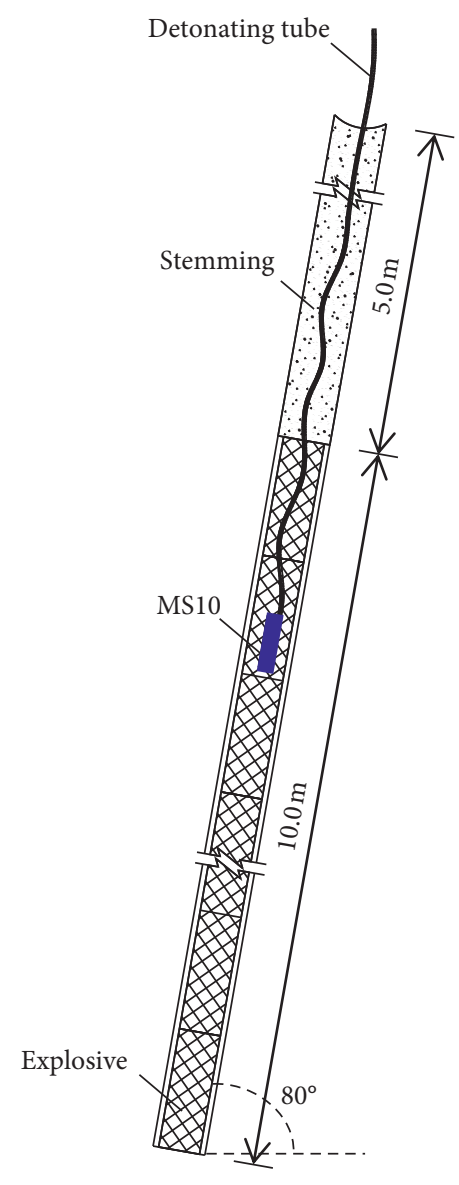

(a)

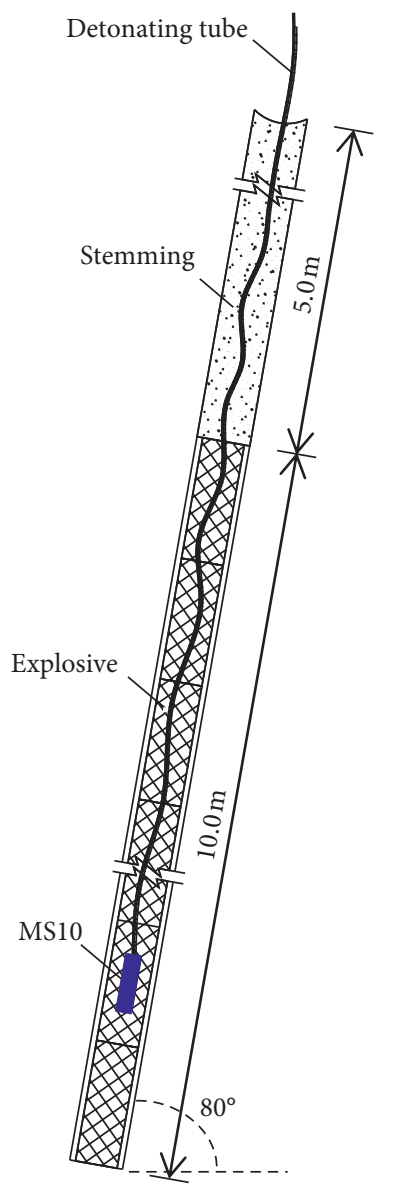

(b)

Figure 25: Charging structures of the single blastholes (a) S1 (top initiated) and (b) S2 (bottom initiated) in the production blasting experiment.

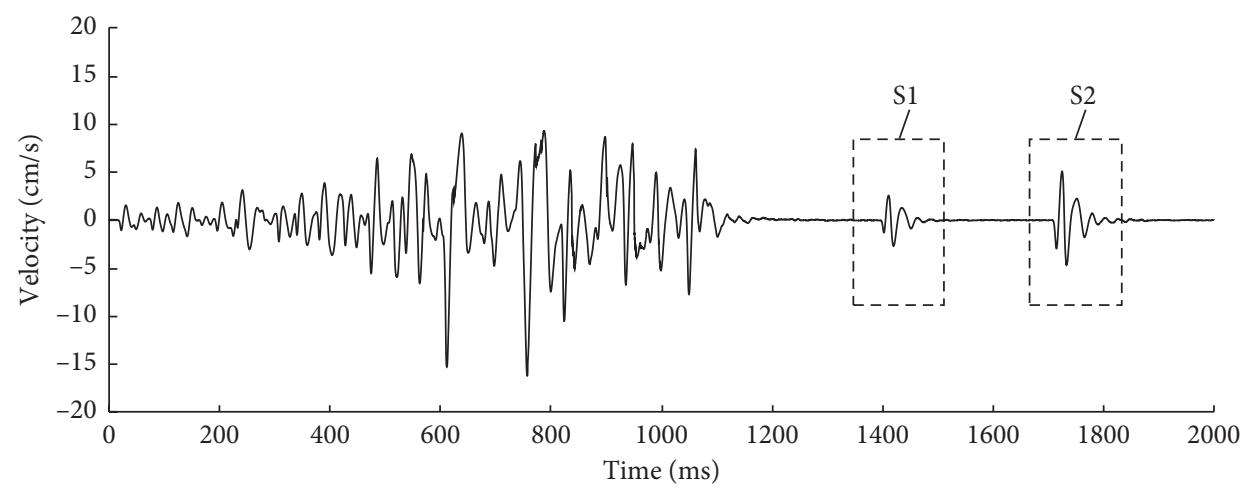

FIgURE 26: Typical blast vibration waveform in the production blasting experiment. 
TABLE 6: Measured PPVs in the production blasting experiment.

\begin{tabular}{|c|c|c|c|c|c|c|c|c|c|}
\hline \multirow{3}{*}{ Sensor no. } & \multirow{3}{*}{$R(\mathrm{~m})$} & \multicolumn{8}{|c|}{ PPV $(\mathrm{cm} / \mathrm{s})$} \\
\hline & & \multicolumn{4}{|c|}{ S1 (top initiated) } & \multicolumn{4}{|c|}{ S2 (bottom initiated) } \\
\hline & & Radial & Tangential & Vertical & Vector & Radial & Tangential & Vertical & Vector \\
\hline$\# 1$ & 26 & 3.21 & 6.63 & 9.62 & 12.12 & 6.26 & 11.38 & 35.46 & 37.76 \\
\hline$\# 2$ & 42.5 & 2.51 & 2.96 & 7.13 & 8.12 & 6.39 & 3.29 & 9.89 & 12.23 \\
\hline$\# 3$ & 53.1 & 1.55 & 1.6 & 2.67 & 3.48 & 4.98 & 2.88 & 5.08 & 7.67 \\
\hline$\# 4$ & 61.2 & 1.57 & 1.17 & 2.5 & 3.18 & 3.38 & 2.51 & 5.14 & 6.64 \\
\hline$\# 5$ & 83.4 & 1.08 & 0.90 & 1.45 & 2.02 & 2.19 & 1.27 & 2.05 & 3.26 \\
\hline
\end{tabular}

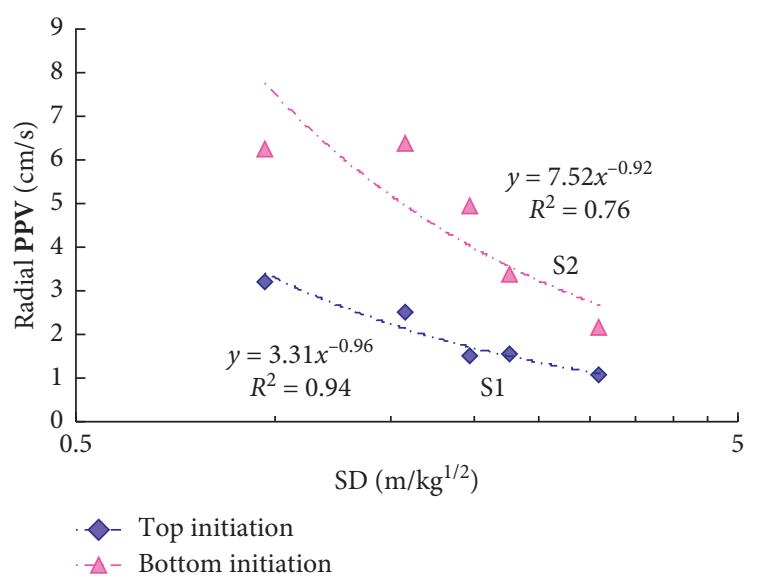

(a)

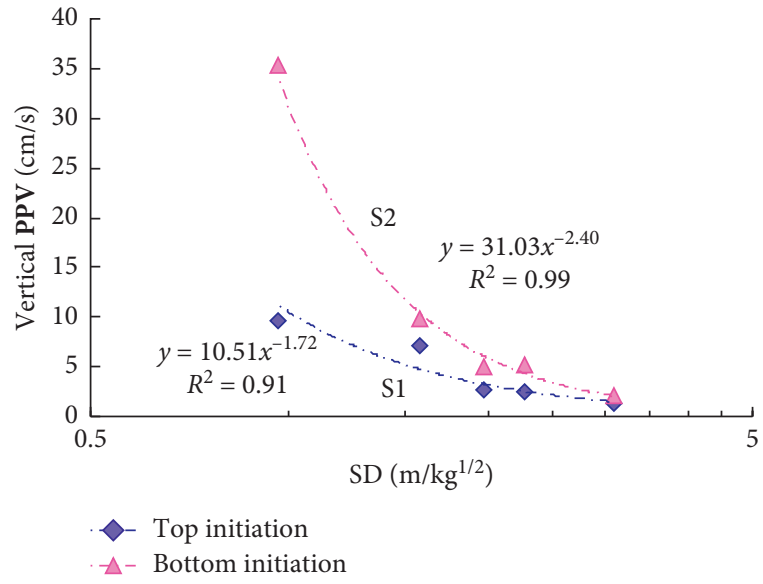

(c)

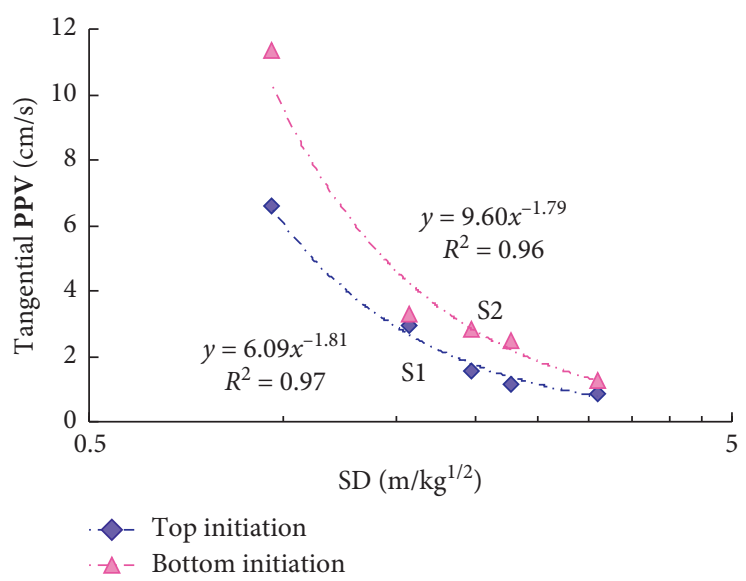

(b)

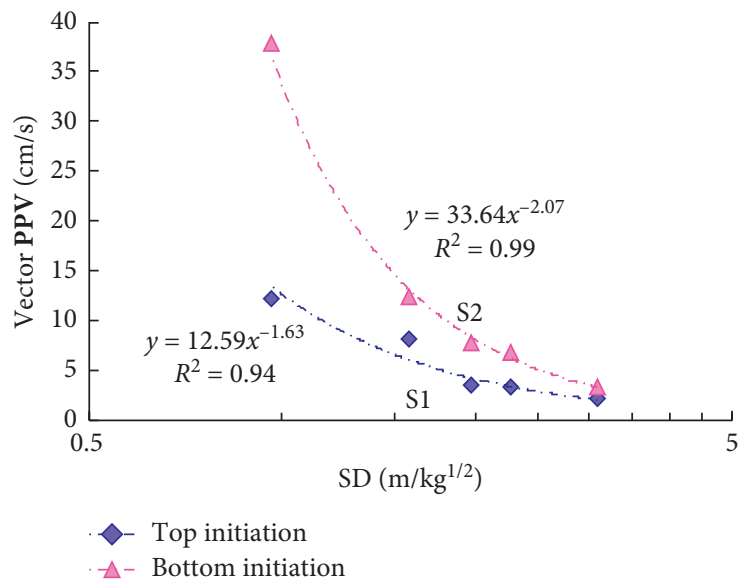

(d)

FIGURe 27: Fitted curves of the PPV against SD in the production blasting experiment. (a) Radial PPV. (b) Tangential PPV. (c) Vertical PPV. (d) Vector PPV.

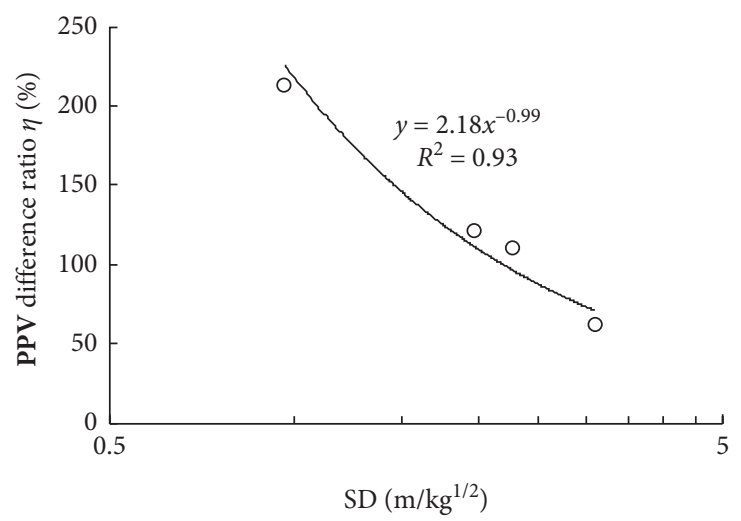

Figure 28: PPV difference ratio of blastholes S1 and S2 in the production blasting experiment. 
Moreover, the effect of the initiation location can be ignored if the observation point is far enough.

\section{Data Availability}

The data used to support the findings of this study are available from the corresponding author upon request.

\section{Conflicts of Interest}

The authors declare that there are no conflicts of interest regarding the publication of this paper.

\section{Acknowledgments}

This work was supported by the Chinese National Natural Science Foundation (nos. 51809016 and 51779190), Chongqing Municipal Natural Science Foundation (no. cstc2019jcyj-msxmX0645), and Visiting Scholar Fund of Key Laboratory of Rock Mechanics in Hydraulic Structural Engineering, Ministry of Education (RMHSE1903). The authors wish to express their thanks to all supporters.

\section{References}

[1] Y. Hu, W. Lu, M. Chen, P. Yan, and J. Yang, "Comparison of blast-induced damage between presplit and smooth blasting of high rock slope," Rock Mechanics and Rock Engineering, vol. 47, no. 4, pp. 1307-1320, 2014.

[2] J. H. Yang, W. B. Lu, Q. H. Jiang, C. Yao, and C. B. Zhou, "Frequency comparison of blast-induced vibration per delay for the full-face millisecond delay blasting in underground opening excavation," Tunnelling and Underground Space Technology, vol. 51, pp. 189-201, 2016.

[3] H. Hu, W. Lu, P. Yan, M. Chen, and Q. Gao, "A vibrationisolating blast technique with shock-reflection device for dam foundation excavation in complicated geological conditions," Shock and Vibration, vol. 2018, Article ID 8029513, 11 pages, 2018.

[4] D. Liu, W. Lu, Y. Liu, M. Chen, P. Yan, and P. Sun, “Analysis of the main factors influencing the dominant frequency of blast vibration," Shock and Vibration, vol. 2019, Article ID 8480905, 17 pages, 2019.

[5] X. Shi, X. Qiu, J. Zhou, D. Huang, X. Chen, and Y. Gou, “A comparative study of ground and underground vibrations induced by bench blasting," Shock and Vibration, vol. 2016, Article ID 2143575, 9 pages, 2016.

[6] C. Knock and N. Davies, "Blast waves from cylindrical charges," Shock Waves, vol. 23, no. 4, pp. 337-343, 2013.

[7] R. S. Fry and J. A. Nicholls, "Blast initiation and propagation of cylindrical detonations in mapp-air mixtures," AIAA Journal, vol. 12, no. 12, pp. 1703-1708, 1974.

[8] M. Sichel, "A simple analysis of the blast initiation of detonations," Acta Astronautica, vol. 4, no. 3-4, pp. 409-424, 1977.

[9] Z. Zhang, "Increasing ore extraction by changing detonator positions in lkab malmberget mine," Fragblast, vol. 9, no. 1, pp. 29-46, 2005.

[10] Y. Long, M. Zhong, Q. Xie, X. Li, K. Song, and K. Liao, "Influence of initiation point position on fragmentation by blasting in iron ore," Rock Fragmentation by Blasting, vol. 10, pp. 111-116, 2012.

[11] I. A. Onederra, J. K. Furtney, E. Sellers, and S. Iverson, "Modelling blast induced damage from a fully coupled explosive charge," International Journal of Rock Mechanics and Mining Sciences, vol. 58, no. 58, pp. 73-84, 2013.

[12] L. Liu, M. Chen, W. Lu, Y. Hu, and Z. Leng, "Effect of the location of the detonation initiation point for bench blasting," Shock and Vibration, vol. 2015, Article ID 907310, 11 pages, 2015.

[13] Z. Leng, W. Lu, M. Chen, Y. Fan, P. Yan, and G. Wang, "Explosion energy transmission under side initiation and its effect on rock fragmentation," International Journal of Rock Mechanics and Mining Sciences, vol. 86, pp. 245-254, 2016.

[14] Q. Gao, W. Lu, P. Yan, H. Hu, Z. Yang, and M. Chen, "Effect of initiation location on distribution and utilization of explosion energy during rock blasting," Bulletin of Engineering Geology and the Environment, vol. 78, no. 5, pp. 3433-3447, 2019.

[15] R. F. Favreau, "Generation of strain waves in rock by an explosion in a spherical cavity," Journal of Geophysical Research, vol. 74, no. 17, pp. 4267-4280, 1969.

[16] P. A. Heelan, "Radiation from a cylindrical source of finite length," Geophysics, vol. 18, no. 3, pp. 685-696, 1953.

[17] D. Jordan, "The stress wave from a finite, cylindrical explosive source," Indiana University Mathematics Journal, vol. 11, no. 4, pp. 503-551, 1962.

[18] J. E. White and R. L. Sengbush, "Shear waves from explosive sources," Geophysics, vol. 28, no. 6, pp. 1001-1019, 1963.

[19] A. M. Abo-Zena, "Radiation from a finite cylindrical explosive source," Geophysics, vol. 42, no. 7, pp. 1384-1393, 1977.

[20] D. Blair, "Seismic radiation from an explosive column," Geophysics, vol. 75, no. 1, pp. 55-65, 2010.

[21] K.-W. Liu, X.-H. Li, X.-B. Li, Z.-H. Yao, Z.-X. Shu, and M.-H. Yuan, "Characteristics and mechanisms of strain waves generated in rock by cylindrical explosive charges," Journal of Central South University, vol. 23, no. 11, pp. 2951-2957, 2016.

[22] L. F. Triviño, B. Mohanty, and B. Milkereit, "Seismic waveforms from explosive sources located in boreholes and initiated in different directions," Journal of Applied Geophysics, vol. 87, no. 12, pp. 81-93, 2012.

[23] P. K. Singh and M. P. Roy, "Damage to surface structures due to blast vibration," International Journal of Rock Mechanics and Mining Sciences, vol. 47, no. 6, pp. 949-961, 2010.

[24] M. Khandelwal, "Evaluation and prediction of blast-induced ground vibration using support vector machine," International Journal of Rock Mechanics and Mining Sciences, vol. 47, no. 3, pp. 509-516, 2010.

[25] O. Dogan, Ö. Anil, S. O. Akbas, E. Kantar, and R. Tuğrul Erdem, "Evaluation of blast-induced ground vibration effects in a new residential zone," Soil Dynamics and Earthquake Engineering, vol. 50, pp. 168-181, 2013.

[26] F. Faramarzi, M. A. Ebrahimi Farsangi, and H. Mansouri, "Simultaneous investigation of blast induced ground vibration and airblast effects on safety level of structures and human in surface blasting," International Journal of Mining Science and Technology, vol. 24, no. 5, pp. 663-669, 2014.

[27] X. Fan, P. H. S. W. Kulatilake, and X. Chen, "Mechanical behavior of rock-like jointed blocks with multi-non-persistent joints under uniaxial loading: a particle mechanics approach," Engineering Geology, vol. 190, no. 5, pp. 17-32, 2015.

[28] H. Chen, X. Fan, H. Lai, Y. Xie, and Z. He, "Experimental and numerical study of granite blocks containing two side flaws and a tunnel-shaped opening," Theoretical and Applied Fracture Mechanics, vol. 104, p. 102394, 2019.

[29] X. Fan, H. Lin, H. Lai, R. Cao, and J. Liu, "Numerical analysis of the compressive and shear failure behavior of rock 
containing multi-intermittent joints," Comptes Rendus Mécanique, vol. 347, no. 1, pp. 33-48, 2019.

[30] B. Zhang, Q. Zhang, and F. Huang, Detonation Physics, Weapon Industry Press, Beijing, China, 2001, in Chinese.

[31] A. M. Starfield and J. M. Pugliese, "Compression waves generated in rock by cylindrical explosive charges: a comparison between a computer model and field measurements," International Journal of Rock Mechanics and Mining Sciences \& Geomechanics Abstracts, vol. 5, no. 1, pp. 65-77, 1968.

[32] D. E. Grady, M. E. Kipp, and C. S. Smith, "Explosive fracture studies on oil shale," Society of Petroleum Engineers Journal, vol. 20, no. 5, pp. 349-356, 1980.

[33] D. B. Larson, "Explosive energy coupling in geologic materials," International Journal of Rock Mechanics and Mining Sciences \& Geomechanics Abstracts, vol. 19, no. 4, pp. 157-166, 1982. 


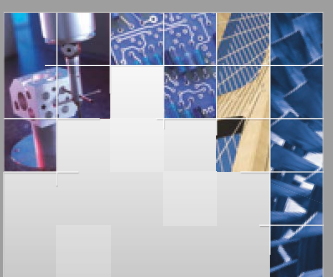

\section{Enfincering}
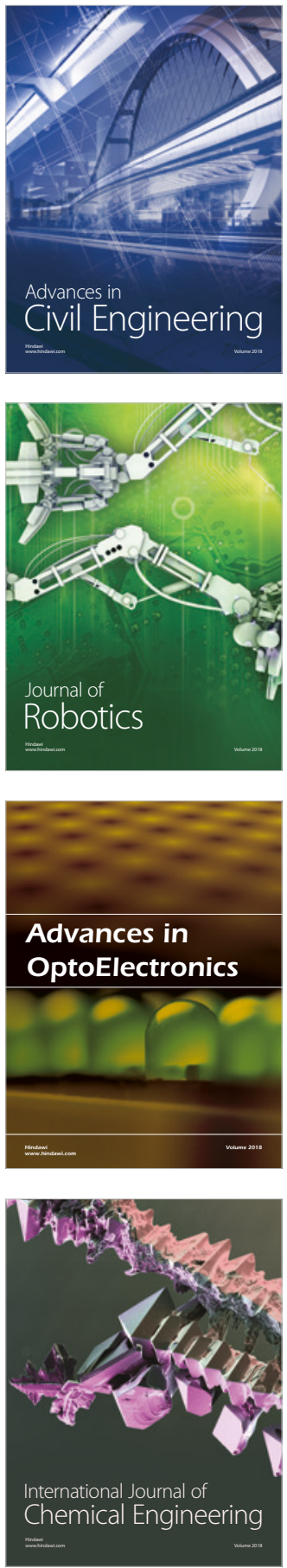

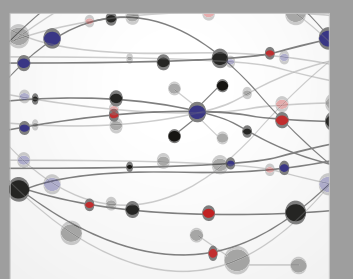

\section{Rotating \\ Machinery}

The Scientific World Journal

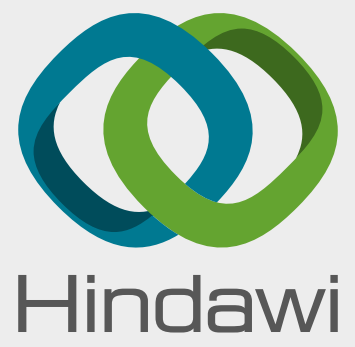

Submit your manuscripts at

www.hindawi.com
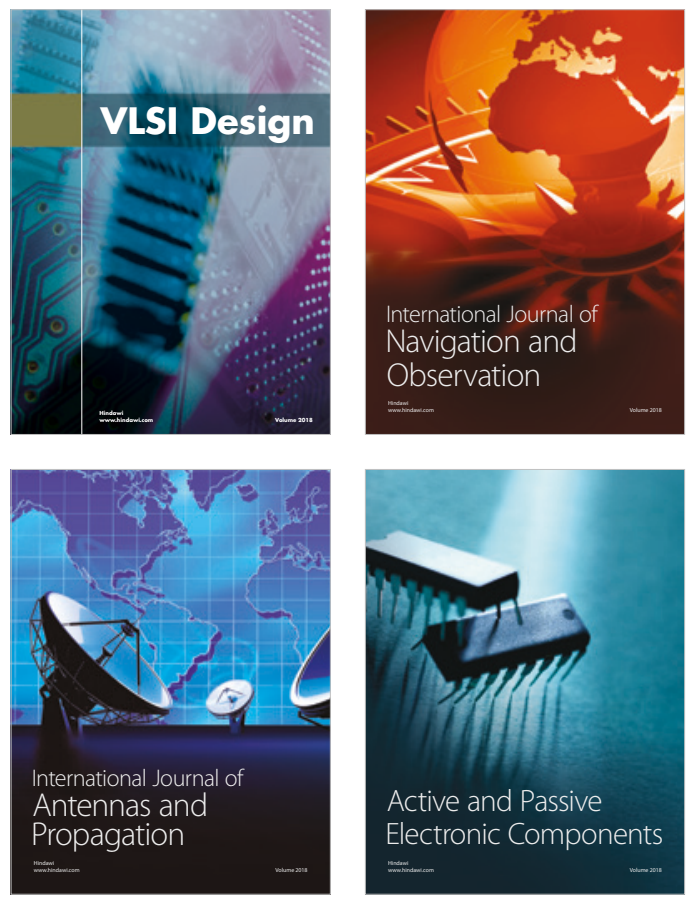
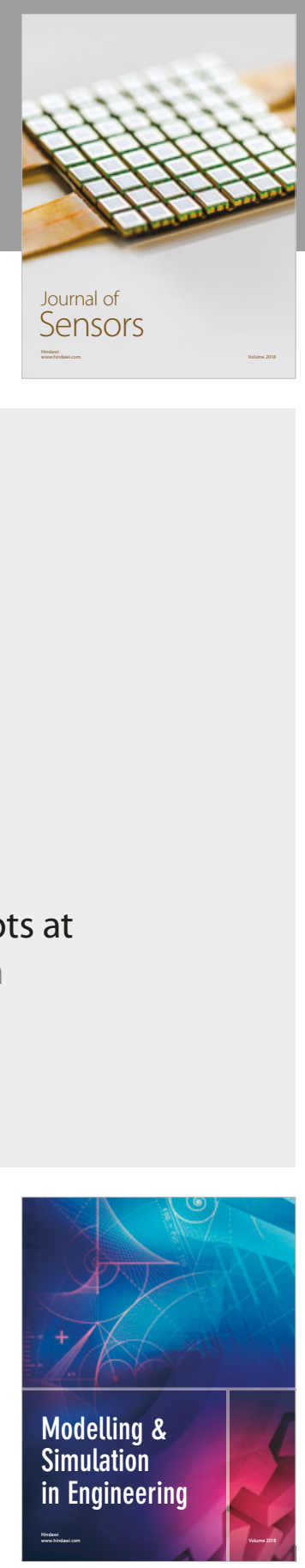

\section{Advances \\ Multimedia}
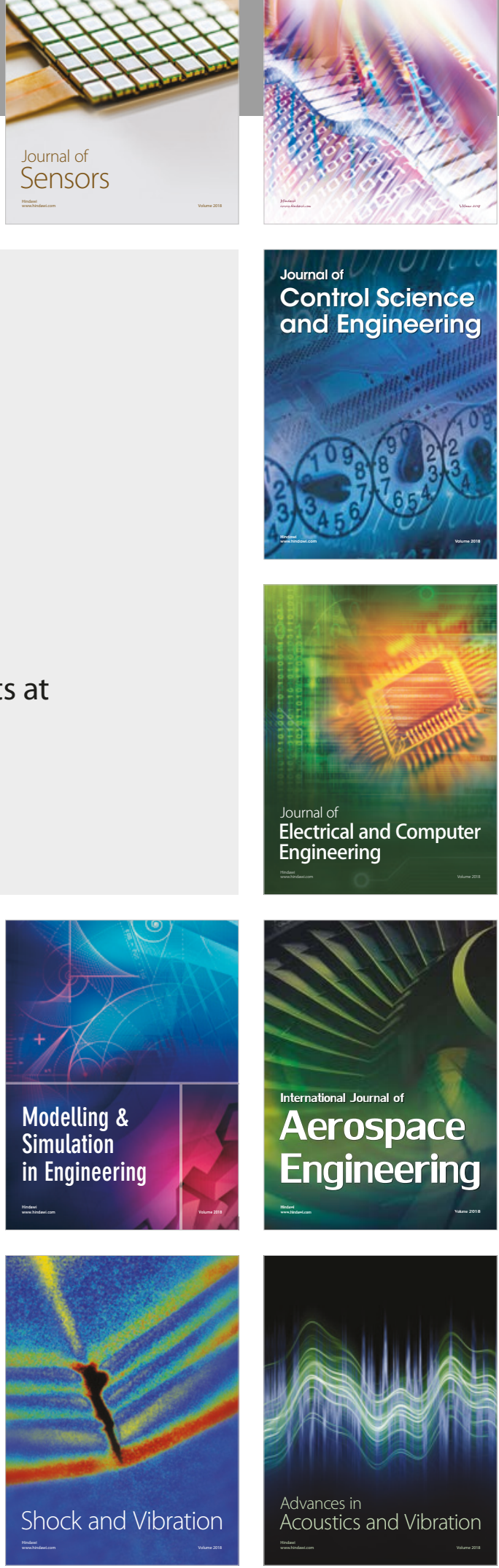